\title{
Preparation of $E$. coli RNA polymerase transcription elongation complexes for systematic RNA assays
}

\section{Eric J. Strobel ${ }^{1 *}$}

From the ${ }^{1}$ Department of Biological Sciences, The University at Buffalo, Buffalo, NY 14260, USA

Running title: E. coli TEC purification and barcoding

*To whom correspondence should be addressed: estrobel@buffalo.edu

Keywords: transcription, RNA polymerase, DNA, promoter, RNA, RNA structure, RNA folding, transcription elongation complex, biotin, TEC Display

\section{Abstract}

RNA folds into secondary and tertiary structures that can mediate diverse cellular functions. Understanding how RNA sequence directs the formation of biologically active structures requires approaches that can comprehensively assess how changes in an RNA sequence affect its structure and function. Towards this goal, I have developed a general method for purifying $E$. coli RNA polymerase (RNAP) transcription elongation complexes (TECs) for use in systematic RNA assays. My approach depends on two constituent technologies: First, I have designed an E. coli $\sigma^{70}$ promoter that can be efficiently barcoded using a one-pot series of enzymatic reactions. Second, I have developed a strategy for purifying promoter-initiated E. coli RNAP TECs by selective photo-elution from streptavidin-coated magnetic beads. Together, these methods establish a platform for the development of TEC Display assays in which the functional properties of RNA sequence variants can be recorded by fractionating and quantitatively barcoding a TEC library. 


\section{Introduction}

RNA molecules perform diverse cellular functions that frequently depend on secondary and tertiary structures

(1). RNA structure formation is dynamic, complex, and begins when RNA is synthesized during transcription

(2-4). Understanding how RNA primary sequence gives rise to biologically active structures therefore requires quantitative methods that can efficiently explore the functional capacity of vast sequence space, cotranscriptionally.

One strategy for comprehensively assessing the function of complex RNA sequence libraries is to couple highthroughput DNA sequencing with in situ transcription on an Illumina sequencer flow cell to perform fluorescence-based RNA assays (5). This approach, which was pioneered by the High-Throughput Sequencing-ㅁNA A ffinity Profiling (HiTS-RAP) (6) and Quantitative Analysis of RNA on a Massively $\underline{\text { Parallel }}$

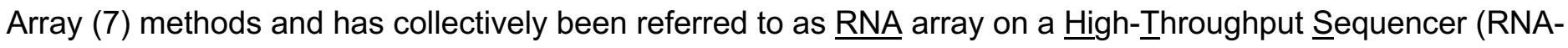
HiTS) (5), leverages the ability of stalled TECs to physically link an RNA transcript to the DNA template from which it was transcribed. In this way, direct measurements of RNA function can be coupled to a DNA sequencing read.

Independent of its technical utility for linking transcribed RNA to its DNA template in RNA-HiTS assays, the cotranscriptional display of RNA is a powerful tool for studies of RNA folding for several reasons. First, RNA molecules begin to fold during transcription $(3,4)$ and cotranscriptionally folded RNA may adopt different structures than renatured RNA (8-10). Second, experiments in which RNA is tethered to its DNA template can circumvent biases from processing steps that are typically required for RNA sequencing libraries, such as ssRNA ligation and reverse transcription, because sequence information can be recovered from the template DNA. Similarly, the presence of a physical link between RNA function and DNA sequence can enable the investigation of intrinsically destructive RNA activities, such as self-cleavage (11), in which RNA sequence information is lost when the RNA performs its biochemical function. Third, direct interactions between a transcribing RNAP and nascent RNA are frequently required for cotranscriptional RNA functions (12-14). Cotranscriptional RNA assays are therefore essential to our understanding of RNA structure and function. 
The application of RNA-MaP and HiTS-RAP to diverse RNA targets illustrates the utility of cotranscriptionally displayed RNA libraries for uncovering the sequence and structural basis of RNA function $(6,7,11,15-20)$. Nonetheless, TEC-based RNA array experiments in which the measurement of RNA function is independent of a sequencing instrument have not been developed. In contrast to RNA-HiTS, an off-sequencer TEC-based RNA assay would necessarily sacrifice the ability to directly measure RNA function. However, an appropriately designed method would retain many of the advantages gained by coupling RNA to DNA, would be accessible to laboratories without the technical expertise for RNA-HiTS assays, and could likely be integrated with other biochemical assays such as RNA structure probing (21) and in vitro selection (22,23). An off-sequencer platform for the development of TEC-based RNA assays would therefore be distinct from and complementary to the established RNA-HiTS methodologies.

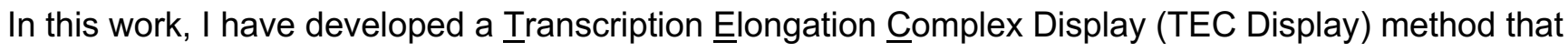
combines TEC purification with quantitative DNA barcoding to establish a platform for the development of systematic RNA assays. First, I describe a derivative of the $\lambda P_{R} \sigma^{70}$ promoter that can be efficiently barcoded in a one-pot, sequence-independent series of enzymatic reactions. I then implement a TEC purification procedure based on my previous observation that stalling E. coli RNAP at an internal desthiobiotin-TEG (or biotin-TEG, as described here) lesion blocks attachment of the biotinylated DNA to streptavidin-coated magnetic beads (24). In this procedure, a DNA template containing both an internal biotin-TEG stall site and a 5' photocleavable biotin (5' PC biotin) is transcribed and attached to streptavidin beads. DNA containing TECs is attached by PC biotin only and can therefore be selectively photo-eluted, whereas DNA without a TEC is retained by the exposed biotin-TEG stall site. My procedures for TEC purification and quantitative DNA barcoding can be integrated seamlessly, and together will enable the development of experiments in which measurements of RNA function are directly coupled to DNA sequence using a TEC library.

\section{$\underline{\text { Results }}$}

\section{Rationale and requirements for TEC Display experiments}

I developed the E. coli $\sigma^{70}$ promoter barcoding and TEC purification methods presented in this work to facilitate in vitro transcription assays in which a DNA library can be fractionated by the function of cotranscriptionally 
displayed RNA. In principle, barcoding the partitioned DNA library with fraction- and molecule-specific sequence identifiers can quantitatively record the activity of each RNA variant as the distribution of its corresponding template DNA between fractions. A successful implementation of this strategy requires that the barcoding reaction is 1) DNA sequence-independent so that it is compatible with complex DNA libraries, 2) efficient and minimally biased, and 3) coupled with a procedure to purify TECs so that only DNA templates that have directed productive transcription are used in the assay. The procedure I have developed achieves these criteria using an extensively modified linear DNA template that contains the following features: First, an internal biotin-TEG modification functions as a chemically encoded stall site for E. coli RNAP (24) and as an attachment point, first for depleting DNA without TECs and subsequently for purifying barcoded DNA; the internal biotin-TEG is embedded in a variant of the Illumina TruSeq Small RNA RP1 primer that was extended by five nucleotides so that it contains the full Illumina RA5 adapter sequence. Second, thermostabilityenhancing dNTPs ensure DNA integrity downstream of the internal biotin-TEG modification during DNA barcoding. Third, a 5' PC biotin enables reversible DNA immobilization for buffer exchanges during TEC purification. Fourth, two deoxyuridine (dU) nucleotides in the promoter can be excised to generate a long 3' overhang for molecular barcoding. The complete layout of a TEC Display DNA template is shown in Figure 1 and the function of sequence elements and DNA modifications are described in detail in the relevant sections below.

\section{dU excision enables a one-pot dsDNA barcoding reaction}

$\mathrm{dU}$ excision is an established method for generating 'sticky' ends in molecular cloning protocols (25). In this approach, the thermolabile $\underline{\text { Uracil-S}}$ pecific Exxcision $\underline{\text { Reagent }}\left(\mathrm{USER}^{\circledR}\right)$ enzyme excises dU nucleotides from DNA through the activity of uracil DNA glycosylase $(26,27)$, which catalyzes excision of the uracil base, and endonuclease III which excises the resulting abasic site leaving a one nucleotide gap with a 5' phosphate $(28,29)$. To facilitate USER ${ }^{\circledR}$-mediated promoter barcoding, I designed the $\mathrm{P}_{\mathrm{RA} 1}$ promoter which is derived from the bacteriophage promoters $\lambda \underline{P_{R}}$ and T7 $\underline{A 1}$ (Fig. 2A). I selected $\lambda P_{R}$ as the primary basis (positions -1 to -35 ) of $P_{R A 1}$ due to the long lifetime of $\lambda P_{R}$ open promoter complexes (30). Sequence upstream of $-35(-36$ to -50$)$ comprises the proximal UP element subsite (31) of the T7A1 promoter to reduce the GC content of this region. I positioned dU nucleotides at -13 (one nucleotide upstream of the -10 element hexamer) and at -30 (the sixth 
bioRxiv preprint doi: https://doi.org/10.1101/2021.03.15.435517; this version posted March 15,2021 . The copyright holder for this preprint (which was not certified by peer review) is the author/funder, who has granted bioRxiv a license to display the preprint in perpetuity. It is made available under aCC-BY-NC-ND 4.0 International license.

nucleotide in the -35 hexamer). These positions were selected purposefully so that to the Tm of the DNA fragments that are formed upon USER ${ }^{\circledR}$ digestion is dramatically lower than that of resulting $3^{\prime}$ overhang in the transcribed DNA strand (Fig. 2A). -29A was changed to C to promote efficient USER ${ }^{\circledR}$ digestion (32).

The $\mathrm{P}_{\mathrm{RA} 1}$ promoter barcoding procedure is as follows (Fig. 2B): First, dU nucleotides in the non-transcribed DNA strand of $\mathrm{P}_{\mathrm{RA} 1}$ are excised by digestion with Thermolabile USER ${ }^{\circledR}$ II enzyme. Following digestion, a barcoding oligonucleotide is competitively annealed to the $\mathrm{P}_{\mathrm{RA} 1}$ transcribed DNA strand by heating to $70^{\circ} \mathrm{C}$ and slowly cooling to $25^{\circ} \mathrm{C}$. The barcoding oligonucleotide used for protocol validation contains an N16 'barcoding region' flanked by $\mathrm{P}_{\mathrm{RA} 1}$ sequence spanning -50 to -13 at the 3 ' end, and the reverse complement of the Illumina TruSeq Small RNA RA3 adapter at the 5' end (Table S1, PRA1m12_VRA5_16N). Thermolabile $\mathrm{USER}^{\circledR}$ II is inactivated during this annealing step. Next, T4 DNA ligase is added to the reaction to ligate the barcoding oligonucleotide to the DNA template and is subsequently heat inactivated. After ligation, the one-pot DNA barcoding procedure is complete and, in experiments that contain fractionated samples, fractions can be pooled so that all downstream manipulations are identical. Excess barcoding oligonucleotide is removed by immobilizing the biotinylated template DNA on streptavidin-coated magnetic beads, removing the supernatant and washing once. The DNA template is then extended to fill the 5 ' overhang generated by the barcoding oligonucleotide. Figure $2 \mathrm{C}$ shows a proof-of-principle barcoding reaction using a 5 ' biotinylated DNA template (DNA Template 1 in Table S2), in which one sample volume was removed after key manipulations to visualize step-by-step processing. Each step is efficient, and no reaction side products are detectable.

\section{$P_{R A 1}$ barcoding is compatible with internally modified DNA}

I previously described a method for preparing internally modified linear dsDNA that can be used to halt transcription elongation by E. coli RNAP for cotranscriptional RNA assays (24). This chemical transcription roadblocking approach enables an RNAP stall site to be functionalized for complex manipulations of the stalled TECs. My protocol for the sequence-independent preparation of internally modified DNA templates uses the commercially available translesion DNA polymerase Sulfolobus DNA polymerase IV (33), which adds 1-2 dA nucleotides to the DNA 3' ends (34). In principle, a 3'-dA overhang could interfere with primer extension during $\mathrm{P}_{\mathrm{RA} 1}$ barcoding. I therefore assessed the compatibility of $\mathrm{P}_{\mathrm{RA} 1}$ barcoding with a DNA template that contains an 
internal biotin-TEG modification (DNA Template 2 in Table S2). After demonstrating that internally biotinylated DNA is efficiently barcoded through the oligonucleotide ligation step (Fig. 2D), I performed the final primer extension step using Klenow Fragment ( $3^{\prime} \rightarrow 5$ ' exo-), Klenow Fragment, and T4 DNA polymerase (Fig. 2E). Because primer extension was efficient for each DNA polymerase, I used Klenow Fragment for all subsequent barcoding experiments due to its proofreading capability and because it is less prone to the formation of 3' recessed ends than T4 DNA polymerase.

Another consideration when barcoding internally modified DNA is whether the relatively short (29 bp) DNA duplex downstream of the modification site remains stable throughout processing, particularly during steps with elevated temperatures such as oligonucleotide annealing. My standard protocol for the preparation of internally modified DNA now uses the thermostability enhancing dNTPs 2-amino-dATP and 5-propynyl-dCTP during translesion synthesis as a safeguard against DNA end-fraying downstream of the modification site. To assess whether undesirable DNA species form during $\mathrm{P}_{\mathrm{RA} 1}$ barcoding, I processed an internally desthiobiotinylated DNA template (DNA Template 3 in Table S2) so that immobilized DNA could be gently eluted from streptavidin-coated magnetic particles by adding free biotin. I observed a complete shift of the dsDNA to the expected length after barcoding and did not observe other DNA species (Fig. 2F), indicating that internally modified dsDNA is a compatible substrate for the $\mathrm{P}_{\mathrm{RA} 1}$ barcoding procedure.

\section{Purification of precisely positioned TECs by selective photo-elution from streptavidin beads}

Transcription initiation is not $100 \%$ efficient (35-37). Consequently, TEC Display experiments must be designed such that DNA templates that do not direct productive transcription are excluded from the assay. To this end, I developed a procedure for purifying E. coli RNAP TECs based on my previous observation that positioning RNAP at an internal desthiobiotin-TEG stall site blocks attachment to streptavidin-coated magnetic beads (24). To verify that positioning a TEC at an internal biotin-TEG stall site blocks streptavidin binding, I assessed the efficiency at which DNA containing an internal biotin-TEG modification was attached to streptavidin beads without and with a single round of transcription. When NTPs were omitted from the transcription reaction, $\sim 97 \%$ of DNA was present in the bead pellet regardless of RNAP concentration, indicating that non-specific binding by excess RNAP did not interfere with DNA immobilization (Fig. 3A, B). The 
bioRxiv preprint doi: https://doi.org/10.1101/2021.03.15.435517; this version posted March 15, 2021. The copyright holder for this preprint

(which was not certified by peer review) is the author/funder, who has granted bioRxiv a license to display the preprint in perpetuity. It is made available under aCC-BY-NC-ND 4.0 International license.

$\sim 3 \%$ of DNA that is not attached to the streptavidin beads likely reflects a DNA population that does not contain the biotin modification or in which the biotin modification was inactivated during oligonucleotide synthesis. When NTPs were included to permit single-round transcription, $~ 55 \%$ of DNA was excluded from the streptavidin beads in all conditions where RNAP was included (Fig. 3B). Consistent with the interpretation that streptavidin bead exclusion is TEC-dependent, the $42 \mathrm{nt}$ RNA transcript that is produced when RNAP is halted at the internal biotin stall site was only observed in the supernatant (Fig. 3B). Given that the DNA template was saturated by open complexes and that transcription is single-round, the exclusion of $\sim 52 \%$ of DNA above background suggests that, under the conditions of this assay, approximately half of $\mathrm{P}_{\mathrm{RA} 1}$ promoter open complexes proceed to productive elongation.

TEC-dependent exclusion from streptavidin beads provides a basis for the purification of TECs but must be coupled with a gentle buffer exchange procedure so that components of the transcription reaction can be depleted prior to downstream assays. To this end, I designed the following purification strategy (Fig. 3C): In addition to the internal biotin-stall site, a 5' PC biotin modification (38) is included in the DNA template (DNA Template 4 in Table S2). If RNAP fails to escape the promoter, the DNA is attached to a magnetic particle both by the internal biotin and the PC biotin; bead immobilization is performed under dilute conditions to maximize the likelihood that both biotin modifications are attached to the same bead (Experimental Procedures). In contrast, if RNAP escapes the promoter the internal biotin modification is sequestered by RNAP so that the DNA is attached to the beads by the PC biotin alone. Consequently, upon irradiation by $365 \mathrm{~nm}$ UV LEDs (Fig. S1), DNA containing a TEC at the internal biotin stall site is eluted into the supernatant and DNA that does not contain a stalled TEC is retained in the bead pellet.

To establish a proof-of-principle for this TEC purification strategy, I used 5 nM DNA template and $0.024 \mathrm{U} / \mu \mathrm{l}$ RNAP in a $25 \mu$ l reaction in order to saturate transcription (Fig. 3A); further optimizations are described in the next Results section. The purification was performed as follows (see Experimental Procedures for complete details): After forming open promoter complexes in the absence or presence of $500 \mu \mathrm{M}$ NTPs, single-round transcription was initiated by the simultaneous addition of $\mathrm{MgCl}_{2}$ to $10 \mathrm{mM}$ and rifampicin. After two minutes of transcription, the reaction was diluted by adding $200 \mu \mathrm{l}$ of Transcription Buffer supplemented with rifampicin 
and mixed with $25 \mu \mathrm{l}$ of $1 \mu \mathrm{g} / \mu \mathrm{l}$ streptavidin beads in Transcription Buffer. This bead-binding mixture was incubated for 1 hour at room temperature with rotation, the beads were pelleted using a magnet stand, and the supernatant was collected as fraction S1. The beads were resuspended in $250 \mu$ of Transcription Buffer supplemented with $1 \mathrm{mM} \mathrm{MgCl}$, pelleted again using a magnet stand, and the wash supernatant was collected as fraction W. The beads were then resuspended in $25 \mu$ of Transcription Buffer supplemented with $1 \mathrm{mM}$ $\mathrm{MgCl}_{2}$ and irradiated with $365 \mathrm{nM}$ UV LEDs ( 10 mW/cm² from four directions) for 5 minutes. The bead pellet was collected as fraction P and the supernatant as fraction S2. In both the absence and presence of NTPS $\sim 17 \%$ of DNA was lost in fraction $\mathrm{S1}$, presumably because the reaction was diluted for bead binding to avoid crosslinking the streptavidin beads with the doubly biotinylated DNA template (Fig. 3D). No nucleic acids were detectable in fraction W, indicating that the buffer exchange step does not incur substantial sample loss (Fig. 3D). In the absence of NTPs, $\sim 2 \%$ of the remaining DNA was present in the bead pellet following UV irradiation, indicating that the majority of DNA is retained on the beads by the internal biotin modification (Fig. 3D). In contrast, when TECs were formed by the inclusion of NTPs, $\sim 46 \%$ of the remaining DNA was present in fraction S2 (Fig. 3D). Consistent with the interpretation that the DNA collected in fraction S2 in the presence of NTPs is due to TEC-dependent streptavidin bead exclusion, the 42 nt RNA transcript was only detectable in fraction S2 (Fig. 3D).

\section{A DNA competitor strategy excludes open complexes from purified TEC DNA}

The proof-of-principle TEC purification shown in Figure 3D used a saturating RNAP concentration to assess the efficiency limit of the preparation. However, because this procedure uses rifampicin to limit transcription to a single round (as opposed to heparin, which could interfere with downstream assays (39)), these conditions are likely non-optimal for the preparation of pure TECs: after promoter escape, free RNAP holoenzyme can bind unoccupied promoters to yield DNA that contains both a TEC and an open complex. Consistent with this expectation, EMSAs of prepared TECs revealed the presence of two bands, suggesting that the preparations contain two distinct species (Fig. 4B, lanes 2 and 3). In support of an interpretation that the faster migrating band corresponds to pure TECs and the slower migrating band corresponds to TECs on DNA with an associated open complex, decreasing the ratio of RNAP to DNA template so that open complex formation was not saturated caused the faster migrating band to become more prominent(Figs. 4A, 4B (lanes 2, 3, and 4)). 
Reactions that used $10 \mathrm{nM}$ DNA template and $0.016 \mathrm{U} / \mu \mathrm{l}$ RNAP nearly eliminated the slower migrating band

(Fig. 4B, lane 4) (note that when preparing TECs with $10 \mathrm{nM}$ DNA, the amount of streptavidin beads was doubled, and the binding reaction diluted to $500 \mu$ l accordingly. See Experimental Procedures).

Following the observation that decreasing the RNAP:DNA ratio increased the homogeneity of TEC preparations, I implemented a DNA competitor strategy to scavenge free RNAP holoenzyme before initiating transcription. Below, 'Target DNA' refers to the doubly biotinylated DNA template that is the intended substrate for TEC purification (DNA Template 4 in Table S2) and 'Competitor DNA' refers to the DNA template used to scavenge free RNAP (DNA Template 5 in Table S2). In this strategy, open complexes are first formed on the Target DNA using $10 \mathrm{nM}$ DNA template and $0.016 \mathrm{U} / \mu \mathrm{R}$ RAP, which alone yielded a fast-migrating product with $\sim 94 \%$ purity (Fig. 4B, lane 4). The transcription reaction is then mixed with Competitor DNA containing the $\mathrm{P}_{\mathrm{RA} 1}$ promoter to scavenge free RNAP in open complexes, and an internal etheno-dA stall site to retain RNAP on the Competitor template if promoter escape succeeds. Visualization of this procedure using Cy3-labelled Target DNA and Cy5-labelled Competitor DNA (DNA Templates 6 and 7 in Table S2, respectively) revealed two populations of Target DNA:RNAP complexes: stable complexes that resisted the Competitor DNA and a distinct population of unstable complexes that were titrated to Competitor DNA (Fig. 4C). The presence of substantial free Competitor DNA after open complex formation suggests that most RNAP is engaged in a complex with DNA (Fig. 4C). As expected, scavenging free RNAP prior to TEC purification further reduced the slow-migrating product so that, in reactions that contained $10 \mathrm{nM}$ Target DNA and $0.016 \mathrm{U} / \mu \mathrm{RNAP}$, the fastmigrating product was consistently $>97 \%$ pure (Figs. 4B (lanes 5 and 6), and S2). Competitor DNA was efficiently removed from the TEC preparations in the S1 fraction (Fig. 4D). It was not possible to determine the fraction of input Target DNA that was present in $\mathrm{S} 1$ because Target and Competitor DNA differ in length by only $14 \mathrm{nt}$, however it is clearly a small fraction relative to bead-bound DNA (Fig. 4D). Of the DNA that bound to the streptavidin beads, $\sim 37 \%$ was released into fraction S2 after photo-elution (Fig. 4D).

To verify that the fast- and slow-migrating products observed by EMSA correspond to pure TECs and TECs with an associated open complex, respectively, I performed a 'USER ${ }^{\circledR}$ footprinting assay' to directly assess promoter accessibility in TECs prepared under different conditions. Because the dU bases in the PA1 promoter 
are in close contact with $\sigma^{70}$, open promoter complexes interfere with USER ${ }^{\circledR}$ digestion even when long (30

min at $37^{\circ} \mathrm{C}$ ) incubation times are used (Fig. 5B, C; compare lanes 2 and 3). When TECs were prepared under conditions that primarily yielded the slow-migrating product, USER ${ }^{\circledR}$ digestion was severely attenuated (Fig.

$5 B, C$; lane 5). In contrast, digestion of TECs that were prepared under conditions that yield a $>97 \%$ pure fastmigrating product were digested as effectively as naked DNA (Fig. 5B, C; lane 7).

\section{Purified TECs are compatible with $P_{\mathrm{RA} 1}$ barcoding}

TEC purification and $\mathrm{P}_{\mathrm{RA} 1}$ barcoding both depend on the internal biotin-TEG modification: during TEC purification, the internal biotin-TEG modification is used both as an RNAP stall site and as an attachment point for depleting DNA that does not contain a TEC (Fig. 3C). During P $\mathrm{RA}_{1}$ barcoding, the internal biotin modification must be available as an attachment point for depleting excess barcoding oligonucleotide (Fig. 2B).

Consequently, compatibility of the TEC purification and $\mathrm{P}_{\mathrm{RA} 1}$ barcoding protocols requires efficient TEC degradation. Most TECs were completely dissociated from DNA following treatment with Thermolabile Proteinase $\mathrm{K}$ and trace amounts of remaining TECs were dissociated after heating to $65^{\circ} \mathrm{C}$ for 10 minutes (Fig. S3A). Similarly, the RNA transcript was readily degraded by treatment with RNase $I_{f}$, which was heatinactivated by heating to $70^{\circ} \mathrm{C}$ for 20 minutes (Fig. S3B). The resulting DNA was then readily processed by the $\mathrm{P}_{\mathrm{RA} 1}$ barcoding protocol and amplified using a standard Illumina RNA PCR Index Primer and an extended version of the Illumina RNA PCR Primer (Table S1), indicating that TEC purification and $\mathrm{P}_{\mathrm{RA} 1}$ barcoding can be integrated using only enzymatic reactions and heat inactivation steps (Fig. S3B).

\section{Discussion}

I have developed an integrated procedure that combines purification of precisely positioned E. coli RNAP TECs with quantitative DNA barcoding. This TEC Display method establishes a platform for the development of multiplexed assays in which a TEC library is partitioned by its functional properties so that the activity of sequence variants can be inferred from their distribution across fractions.

In the present study, I have established procedures for the front (TEC purification) and back (quantitative DNA barcoding) ends of TEC Display experiments. Application of TEC Display to address biological questions will 
depend on the development of 'fractionation-by-function' approaches for assessing RNA activity. In principle, the TEC Display platform described here could be applied to study the basis of interactions between RNA and other biomolecules such as proteins (40), small molecules (41), and other RNAs (42). Neither the concept of assessing RNA function using cotranscriptionally displayed sequence libraries nor the concept of fractionating an RNA library by its affinity for an immobilized target are new: RNA-HiTS experiments assess RNA function by cotranscriptionally displaying RNA libraries in situ on an Illumina sequencer flow cell for fluorescence-based assays (6,7), and RNA Bind-n-Seq (RBNS) quantifies RNA-binding protein specificity by fractionating an RNA library based on its affinity for a target protein (43). The central advance of the work presented here is that, by integrating TEC purification with quantitative DNA barcoding, TEC Display combines features of its predecessors in a way that will enable assays that use cotranscriptionally displayed RNA libraries to be performed at the laboratory bench.

TEC Display was designed with an emphasis on broad accessibility, the potential for scalability, and versatility. TEC purification and DNA barcoding can be performed with commercially available reagents and, with the exception of a custom-built $365 \mathrm{~nm}$ UV microcentrifuge tube irradiator (Fig. S1), common laboratory equipment. It should therefore be possible for any laboratory with biochemistry or molecular biology expertise to use or develop TEC Display assays. Towards the goal of scalability, TEC Display makes extensive use of magnetic bead immobilization and thermolabile enzymes to circumvent the need for organic extractions or precipitations. It is therefore likely that TEC Display procedures can be automated. Furthermore, TEC display is immediately compatible with cotranscriptional RNA structure probing methods $(9,44)$ and can likely be integrated into in vitro selection workflows $(22,23)$. For these reasons I anticipate that, through its application and continued technical expansion, TEC Display will complement existing approaches for systematic analysis of cotranscriptionally displayed RNA.

The experimental procedures described here are enabled by a method I previously developed for the sequence-independent preparation of internally modified dsDNA, which can be used to halt RNAP one nucleotide upstream of a functionalized chemical lesion (24). TEC Display provides the first example of how this chemical transcription roadblocking approach can facilitate intricate manipulations of macromolecular 
bioRxiv preprint doi: https://doi.org/10.1101/2021.03.15.435517; this version posted March 15, 2021. The copyright holder for this preprint

(which was not certified by peer review) is the author/funder, who has granted bioRxiv a license to display the preprint in perpetuity. It is made available under aCC-BY-NC-ND 4.0 International license.

complexes: In the combined TEC purification and DNA barcoding procedure, the internal biotin-TEG

modification functions first as a transcription stall site, then as a means for selecting TECs, and finally as an

attachment point for purifying the barcoded DNA library away from excess reaction components. Furthermore, an etheno-dA stall site $(24,45)$ in the competitor DNA used to scavenge free RNAP during open complex formation is used to trap any RNAP that escapes the promoter upon transcription initiation. Currently four DNA modifications have been validated for transcription roadblocking using internally modified DNA, and extension of this approach to include other DNA modifications with distinct functions will further expand our ability to manipulate TECs in complex procedures.

Beyond its immediate applications for TEC Display, my procedure for purifying TECs by selective photo-elution may be generally useful for studies that involve assembling transcription complexes in vitro. Structural and biochemical investigations that require the assembly of defined TECs have classically used a 'scaffold' approach in which ternary complexes are assembled by the sequential addition of nucleic acid and protein components $(46,47)$. For many applications this approach is optimal, however some biologically important transcription complexes may require co-transcriptional or promoter-directed assembly. In such cases, my selective photo-elution method provides a straightforward strategy for bead-based preparation of defined TECs following promoter-directed transcription initiation. Furthermore, while the procedures I have presented here focus on the purification of TECs, it is likely that different DNA modification configurations can facilitate the preparation of other transcription complexes.

\section{Experimental Procedures}

\section{Oligonucleotides}

All oligonucleotides were purchased from Integrated DNA Technologies (IDT). A detailed description of all oligonucleotides including sequence, modifications, and purifications is presented in Table S1.

Oligonucleotides and DNA preparations that contained a 5' PC biotin modification were handled under low intensity $592 \mathrm{~nm}$ light from SimpleColor ${ }^{\top M}$ Amber LEDs (Waveform Lighting) out of an abundance of caution and stored as single-use aliquots. Cy3- and Cy5-labelled oligonucleotides and DNA preparations were handled under low intensity room light and stored as single-use aliquots.

\section{Proteins}

All enzymes, including Q5 ${ }^{\circledR}$ High-Fidelity DNA Polymerase, Q5U ${ }^{\circledR}$ High-Fidelity DNA Polymerase, Vent ${ }^{\circledR}$ (exo-) DNA polymerase, Sulfolobus DNA Polymerase IV, Thermolabile Exonuclease I, Klenow Fragment (3' $\rightarrow 5^{\prime}$ exo), Klenow Fragment, T4 DNA Polymerase, Thermolabile USER ${ }^{\circledR}$ II Enzyme, T4 DNA Ligase, E. coli RNA Polymerase holoenzyme, Thermolabile Proteinase $\mathrm{K}$, and RNase $\mathrm{I}_{\mathrm{f}}$ were purchased from New England Biolabs (NEB). 


\section{Sequences}

Annotated sequences of the constant regions required for TEC Display can be viewed at https://benchling.com/s/seq-DOgBWf14L74Gd9rVv7nc. The sequence of a TEC Display library after barcoding and PCR amplification with full annotations can be viewed at https://benchling.com/s/seqQAf9ODTHtJT1S7aNJ49R. Illumina adapter sequences are from the TrueSeq Small RNA kit. In the sequence annotations, VRA3 is the reverse complement of the Illumina RA5 adapter, and VRA5 is the reverse complement of the Illumina RA3 adapter; this notation was originally used in the Precision Run-On Sequencing method $(48,49)$.

\section{DNA template preparation}

Several DNA template preparation protocols were performed depending on the requirements of oligonucleotide modifications. For simplicity, each possible processing step is detailed below in general terms, and Table S2 provides details on the oligonucleotides and specific processing steps used for every DNA template preparation in this work. All DNA templates that required translesion synthesis were assessed by both denaturing and non-denaturing PAGE quality control analyses, which are shown in Figure S4.

PCR Amplification. DNA templates with dU bases were prepared using Q5U ${ }^{\circledR}$ High-Fidelity DNA Polymerase (NEB) in reactions that contained 1X Q5 ${ }^{\circledR}$ Buffer (NEB), $0.2 \mathrm{mM}$ dNTPs (Invitrogen) , $0.25 \mu \mathrm{M}$ forward primer, $0.25 \mu \mathrm{M}$ reverse primer, $20 \mathrm{pM}$ template oligonucleotide, and $0.02 \mathrm{U} / \mu \mathrm{l} \mathrm{Q} 5 \mathrm{U}^{\circledR}$. Details of the oligonucleotides used for each DNA template preparation are available in Tables S1 and S2. DNA templates that did not contain dU bases were prepared in a reaction that used Q $5^{\circledR}$ High-Fidelity DNA Polymerase (NEB) but was otherwise identical. Typically, six $100 \mu \mathrm{l}$ reaction volumes were prepared on ice and aliquoted into $200 \mu \mathrm{l}$ thinwalled tubes. The thermal cycling protocol was: $98{ }^{\circ} \mathrm{C}$ for $30 \mathrm{~s},\left[98^{\circ} \mathrm{C}\right.$ for $10 \mathrm{~s}, 65^{\circ} \mathrm{C}$ for $20 \mathrm{~s}, 72{ }^{\circ} \mathrm{C}$ for $\left.20 \mathrm{~s}\right] \mathrm{x}$ 30 cycles, $72{ }^{\circ} \mathrm{C}$ for 5 minutes, hold at $12^{\circ} \mathrm{C}$.

Translesion Synthesis. After PCR amplification, DNA templates that required translesion synthesis were purified using a QIAquick ${ }^{\circledR}$ PCR Purification Kit (Qiagen) (1 column per $100 \mu$ reaction) and eluted in $50 \mu$ of Buffer EB (10 mM Tris pH 8.5); one negative control reaction was eluted in $30 \mu$ of Buffer EB and not processed further. This PCR purification step is required to exchange the reaction buffer and deplete dNTPs. $500 \mu \mathrm{l}$ translesion synthesis reactions contained 1X ThermoPol ${ }^{\circledR}$ Buffer (NEB), $200 \mu \mathrm{M}$ dGTP (Invitrogen), 200 $\mu \mathrm{M}$ dTTP (Invitrogen), $200 \mu \mathrm{M}$ 2-Amino-dATP (TriLink Biotechnologies), $200 \mu \mathrm{M}$ 5-Propynyl-dCTP (TriLink Biotechnologies), $0.02 \mathrm{U} / \mu \mathrm{l} \mathrm{Vent}{ }^{\circledR}$ (exo-) DNA Polymerase, and $0.02 \mathrm{U} / \mu \mathrm{l}$ Sulfolobus DNA Polymerase IV and were split into $100 \mu \mathrm{l}$ reaction volumes in $200 \mu \mathrm{l}$ thin-walled tubes. Translesion synthesis reactions were incubated at $55^{\circ} \mathrm{C}$ in a thermal cycler with a heated lid set to $105^{\circ} \mathrm{C}$ for 1 hour.

DNA purification by agarose gel extraction. Agarose gel purification was performed essentially as described previously (24). Five $100 \mu \mathrm{l} \mathrm{PCR}$ or translesion synthesis reactions were pooled and ethanol precipitated by adding $50 \mu \mathrm{l}$ of $3 \mathrm{M}$ sodium acetate ( $\mathrm{NaOAc})(\mathrm{pH} 5.5)$ and $1 \mathrm{ml}$ of cold $100 \%$ ethanol and chilled at $-70{ }^{\circ} \mathrm{C}$ for 30 minutes before centrifugation at $18,500 \times \mathrm{g}$ and $4{ }^{\circ} \mathrm{C}$ for 30 minutes. Pelleted DNA was washed with $1 \mathrm{ml}$ of cold $70 \%$ ethanol, air-dried, and resuspended in $30 \mu \mathrm{l}$ of $10 \mathrm{mM}$ Tris- $\mathrm{HCl}(\mathrm{pH} 8.0)$. Samples were mixed with 6X XC Only SDS DNA Loading Dye (30\% glycerol, $10 \mathrm{mM}$ Tris-HCl (pH 8.0), $0.48 \%$ (w/v) sodium dodecyl sulfate (SDS), $0.01 \%$ xylene cyanole FF), run on a tris-borate-EDTA (TBE) $1 \%(\mathrm{wt} / \mathrm{v}$ ) agarose gel that was prepared using SeaKem ${ }^{\circledR}$ GTG Agarose (Lonza Bioscience) and contained $0.625 \mu \mathrm{g} / \mathrm{ml}$ ethidium bromide. All DNA was able to be excised without UV exposure because the co-migration of ethidium bromide made the large quantity of DNA readily observable under visible light. DNA was purified using a QIAquick ${ }^{\circledR}$ Gel Extraction Kit (Qiagen) according to the manufacturer's protocol, except that agarose gel slices were melted at $30{ }^{\circ} \mathrm{C}$ and the DNA was eluted in $30 \mu \mathrm{l}$ of $10 \mathrm{mM}$ Tris- $\mathrm{HCl}\left(\mathrm{pH}\right.$ 8.0). DNA concentration was quantified using a Qubit ${ }^{\mathrm{TM}} 4.0$ Fluorometer (Invitrogen) with the Qubit ${ }^{\mathrm{TM}}$ dsDNA Broad Range Assay Kit (Invitrogen) according to the manufacturer's protocol.

DNA clean-up by exonuclease digestion. All DNA containing light-sensitive modifications was purified using an alternate protocol that used exonuclease digestion to degrade trace amounts of excess primers in place of gel extraction to minimize light exposure. This procedure was possible because all DNA was prepared using an 
oligonucleotide as the PCR template, so it was not necessary to remove plasmid DNA. PCR or translesion synthesis reactions were pooled and $0.5 \mu$ of Thermolabile Exonuclease I (NEB) was added per $100 \mu \mathrm{l}$ reaction volume. Reactions were incubated $37^{\circ} \mathrm{C}$ for 4 minutes using a thermal cycler and placed on ice. The thermal cycler block was set to $80^{\circ} \mathrm{C}$ and, after it reached temperature, the reactions were returned to the block for 1 minute to heat inactivate the Thermolabile Exonuclease I. The reactions were then purified using a QIAquick PCR Purification Kit (up to 2.5 reactions per column) following the manufacturer's protocol, except that two $750 \mu \mathrm{l}$ Buffer PE washes were performed, and the samples were eluted in $50 \mu \mathrm{l}$ of $10 \mathrm{mM} \mathrm{Tris- \textrm {HCl }}$ ( $\mathrm{pH}$ 8.0). The concentration of purified DNA was quantified using a Qubit ${ }^{\mathrm{TM}}$ 4.0 Fluorometer with the Qubit ${ }^{\mathrm{TM}}$ dsDNA Broad Range Assay Kit according to the manufacturer's protocol. It is important to note that the Thermolabile Exonuclease I digestion was able to be performed immediately following translesion synthesis because primers were depleted to undetectable levels during the Q5U ${ }^{\circledR}$ and Q5 ${ }^{\circledR}$ PCRs (Fig. S4). My laboratory has observed that under PCR amplification conditions that do not lead to virtually complete primer depletion, the presence of excess oligonucleotides and dNTPs can lead to the formation of primer dimers because Sulfolobus DNA polymerase IV is active at $37^{\circ} \mathrm{C}$, which permits the formation of primer dimer products that do not form at higher temperatures. In DNA preparations where primers are not depleted during PCR, this issue is resolved simply by performing an additional PCR clean-up immediately after the translesion synthesis reaction to remove the DNA polymerases and free dNTPs.

\section{Preparation of streptavidin-coated magnetic beads for $\mathrm{P}_{\mathrm{RA} 1}$ barcoding assays}

For $\mathrm{P}_{\mathrm{RA} 1}$ barcoding assays $10 \mu \mathrm{l}$ of Dynabeads ${ }^{\mathrm{TM}}$ MyOne ${ }^{\mathrm{TM}}$ Streptavidin $\mathrm{C} 1$ beads (Invitrogen) per $25 \mu \mathrm{l}$ sample volume were prepared in bulk: After placing the beads on a magnet stand and removing the storage buffer, the beads were resuspended in $500 \mu$ of Hydrolysis Buffer $(100 \mathrm{mM} \mathrm{NaOH}, 50 \mathrm{mM} \mathrm{NaCl})$ and incubated at room temperature for 10 minutes with rotation. Hydrolysis Buffer was removed, and the beads were resuspended in $1 \mathrm{ml} \mathrm{High} \mathrm{Salt} \mathrm{Wash} \mathrm{Buffer} \mathrm{(50} \mathrm{mM} \mathrm{Tris-} \mathrm{HCl}(\mathrm{pH} 7.5), 2 \mathrm{M} \mathrm{NaCl}, 0.5 \%$ Triton X-100), transferred to a new tube, and washed by rotating for 5 minutes at room temperature. High Salt Wash Buffer was removed, and the beads were resuspended in $1 \mathrm{ml}$ Binding Buffer (10 mM Tris- $\mathrm{HCl}(\mathrm{pH} 7.5), 300 \mathrm{mM}$ $\mathrm{NaCl}, 0.1 \%$ Triton X-100), transferred to a new tube, and washed by rotating for 5 minutes at room temperature. Binding buffer was removed, and the beads were resuspended in $25 \mu \mathrm{l}$ of per sample of Binding Buffer and transferred to a new tube. Beads were prepared fresh for each experiment and kept on ice until use.

\section{$P_{\mathrm{RA} 1}$ barcoding validation assays}

The barcoding reaction validation assays in Figure 2 were performed using a single master mix from which fractions were taken during processing to visualize intermediate steps. The volume of an individual sample within the master mix was $25 \mu \mathrm{l}$. For clarity and simplicity, the procedure below specifies the volume of each reagent added to the master mix per $25 \mu \mathrm{l}$ sample volume. A description of the intermediate fractions that were collected is provided at the end of this sub-section.

The barcoding reaction master mix contained 1X T4 DNA Ligase Buffer (NEB) $(2.5 \mu \mathrm{l} / \mathrm{sample}$ volume of 10X T4 DNA Ligase Buffer), $5 \mathrm{nM}$ DNA template $\left(0.125 \mathrm{pmol} / \mathrm{sample}\right.$ volume), and $0.02 \mathrm{U} / \mu \mathrm{l}$ Thermolabile USER ${ }^{\circledR}$ II Enzyme (NEB) $(0.5 \mu \mathrm{l} / \mathrm{sample}$ volume) and was prepared on ice in a thin-walled $200 \mu \mathrm{l}$ tube. The dU excision reaction was incubated at $37^{\circ} \mathrm{C}$ for $30 \mathrm{~min}$ on a thermal cycler block with a heated lid set to $45^{\circ} \mathrm{C}$. After dU excision, $0.5 \mu \mathrm{l} /$ sample volume of $2.5 \mu \mathrm{M}$ barcoding oligo PRA1m12_VRA5_16N (Table S1) was added to the master mix. To anneal the barcoding oligo and inactivate Thermolabile USER ${ }^{\circledR}$ II Enzyme, the master mix was placed on a thermal cycler block set to $70^{\circ} \mathrm{C}$ with a heated lid set to $105^{\circ} \mathrm{C}$ and slowly cooled using the protocol: $70{ }^{\circ} \mathrm{C}$ for 5 minutes, ramp to $65^{\circ} \mathrm{C}$ at $0.1^{\circ} \mathrm{C} / \mathrm{s}, 65^{\circ} \mathrm{C}$ for 5 minutes, ramp to $60{ }^{\circ} \mathrm{C}$ at $0.1{ }^{\circ} \mathrm{C} / \mathrm{s}, 60^{\circ} \mathrm{C}$ for 2 minutes, ramp to $25^{\circ} \mathrm{C}$ at $0.1^{\circ} \mathrm{C} / \mathrm{s}$, hold at $25^{\circ} \mathrm{C}$. After annealing the barcoding oligo, $1 \mu \mathrm{l} / \mathrm{sample}$ volume of T4 DNA ligase (NEB) was added to the master mix. The ligation reaction was incubated at $25^{\circ} \mathrm{C}$ for 1 hour, and T4 DNA ligase was inactivated by incubation at $65^{\circ} \mathrm{C}$ for 10 minutes.

After the ligation step was completed, the master mix was transferred to a $1.7 \mathrm{ml}$ microcentrifuge tube and mixed with $26.5 \mu \mathrm{l} /$ sample volume of $2 X$ Binding Buffer $(20 \mathrm{mM}$ Tris- $\mathrm{HCl},(\mathrm{pH} 7.5), 600 \mathrm{mM} \mathrm{NaCl}, 0.2 \%$ Triton $X-100)$. Pre-equilibrated streptavidin-coated magnetic beads were placed on a magnet stand and the Binding Buffer used for bead storage was removed. The beads were resuspended with the master mix and incubated at room temperature with rotation for 30 minutes. After bead binding, the sample was briefly spun down in a 
mini centrifuge and placed on a magnet stand for 1 minute. The supernatant was removed, and the sample was briefly spun down a second time and returned to the magnet stand for removal of residual supernatant. The sample was then resuspended in $100 \mu \mathrm{l} /$ sample volume of $1 \mathrm{X}$ NEBuffer 2 (NEB) supplemented with Triton $\mathrm{X}-100$ to $0.1 \%$ and transferred to a new tube. If the master mix still contained multiple sample volumes at this point, it was divided into individual $100 \mu \mathrm{l}$ samples. Samples were incubated at room temperature with rotation for 5 minutes, briefly spun down, and placed on a magnet stand for 1 minute. The supernatant was removed, and the samples were briefly spun down a second time and returned to the magnet stand to remove residual supernatant. The beads were then resuspended in $100 \mu \mathrm{l}$ of Extension Master Mix, which varied by experiment.

$100 \mu$ l extension reactions were performed with Klenow Fragment ( $3^{\prime} \rightarrow 5^{\prime}$ exo-) (NEB) (Figs. 2C, 2E), Klenow Fragment (NEB) (Fig. 2E, 2F), or T4 DNA Polymerase (NEB) (Fig. 2E). Klenow Fragment (3' $\rightarrow 5^{\prime}$ exo-) reactions contained $1 X$ NEBuffer 2, $0.2 \mathrm{mM}$ dNTPs, and $0.1 \mathrm{U} / \mu \mathrm{l} \mathrm{Klenow}$ Fragment (3' $\rightarrow 5^{\prime}$ exo-) and were incubated at $25^{\circ} \mathrm{C}$ for 15 minutes followed by $37^{\circ} \mathrm{C}$ for 15 minutes. Klenow Fragment reactions contained $1 \mathrm{X}$ NEBuffer 2, $0.2 \mathrm{mM}$ dNTPs, and $0.05 \mathrm{U} / \mu \mathrm{l}$ Klenow Fragment, and were incubated at $25^{\circ} \mathrm{C}$ for 20 minutes. T4 DNA Polymerase reactions contained 1X NEBuffer 2.1 (NEB), $0.2 \mathrm{mM}$ dNTPs and $0.03 \mathrm{U} / \mu \mathrm{l} \mathrm{T4}$ DNA Polymerase and were incubated at $12^{\circ} \mathrm{C}$ for 20 minutes. Following extension, the reactions were transferred to a pre-chilled $1.7 \mathrm{ml}$ microcentrifuge tube, placed on a magnet stand, and the supernatant was removed. The barcoded DNA was then eluted from the beads using either a denaturing or non-denaturing procedure: DNA containing either a 5 ' or internal biotin modification was recovered by resuspending the bead pellet in $25 \mu \mathrm{l}$ of $95 \%$ formamide and $10 \mathrm{mM}$ EDTA, heating at $100{ }^{\circ} \mathrm{C}$ for five minutes, placing the sample on a magnet stand, and collecting the supernatant. DNA containing an internal desthiobiotin was recovered by resuspending the bead pellet in $150 \mu$ of Biotin Elution Buffer (0.5 M Tris-HCl (pH 8.0), 10 mM EDTA (pH 8.0), 10\% DMSO, 2 $\mathrm{mM}$ D-Biotin), incubating at room temperature with rotation for 15 minutes, placing the sample on a magnet stand, and collecting the supernatant.

Intermediate fractions were collected during the barcoding protocol as follows: Unprocessed control fractions were collected by transferring $24.5 \mu \mathrm{l}$ of the initial master mix to $125 \mu \mathrm{l}$ of Stop Solution $(0.6 \mathrm{M} \mathrm{Tris}-\mathrm{HCl}(\mathrm{pH}$ 8.0), 12 mM EDTA (pH 8.0)) before Thermolabile USER ${ }^{\circledR}$ II Enzyme was added. USER ${ }^{\circledR}$ digested fractions were collected by transferring $25 \mu \mathrm{l}$ of master mix to $125 \mu \mathrm{l}$ of Stop Solution after the dU excision reaction. Barcode ligated fractions were collected by transferring $26.5 \mu \mathrm{l}$ of master mix to $125 \mu \mathrm{l}$ of Stop Solution after T4 DNA ligase was inactivated. Wash fractions were collected by transferring a wash supernatant volume that corresponded to one sample to Stop Solution for a total volume of $150 \mu$ l. Fully barcoded fractions that were eluted from beads by heat denaturation were collected by transferring the $25 \mu$ l supernatant to $125 \mu$ of Stop Solution. Fully barcoded fractions that were eluted in $150 \mu \mathrm{l}$ of Biotin Elution Buffer were collected directly.

All fractions were processed as follows: $150 \mu$ of Tris ( $\mathrm{pH} 8)$ buffered phenol:chloroform:isoamyl alcohol $(25: 24: 1, v / v)$ (Thermo Scientific) was added to each sample. Samples were mixed by vortexing and inversion and centrifuged at $18,500 \times \mathrm{g}$ and $4{ }^{\circ} \mathrm{C}$ for five minutes. The aqueous phase was collected and transferred to a new tube. DNA was precipitated by adding $15 \mu \mathrm{l} 3 \mathrm{M} \mathrm{NaOAc}$ (pH 5.5), $450 \mu \mathrm{l} 100 \%$ ethanol, and $1.5 \mu \mathrm{l}$ GlycoBlue ${ }^{\mathrm{TM}}$ Coprecipitant (Invitrogen) to each sample. The samples were chilled at $-70{ }^{\circ} \mathrm{C}$ for 30 minutes and centrifuged at $18,500 \times \mathrm{g}$ and $4{ }^{\circ} \mathrm{C}$ for 30 minutes. Samples for denaturing PAGE were resuspended in $32 \mu \mathrm{l}$ of Formamide Loading Dye (90\% (v/v) deionized formamide, 1X Transcription Buffer (see below), 0.025\% (w/v) bromophenol blue, $0.025 \%(\mathrm{w} / \mathrm{v})$ xylene cyanole FF); half the sample was used for denaturing PAGE. Samples for native PAGE were resuspended in $10 \mu \mathrm{l}$ of $10 \mathrm{mM}$ Tris- $\mathrm{HCl}(\mathrm{pH} 8.0)$ and $2 \mu \mathrm{l}$ of $6 \mathrm{X}$ DNA loading dye (30\% (v/v) glycerol, $0.025 \%(\mathrm{w} / \mathrm{v})$ bromophenol blue, 0.025\% (w/v) xylene cyanole FF).

\section{Denaturing Urea-PAGE}

Gels for Urea-PAGE were prepared at $10 \%$ or $12 \%$ using the SequaGel UreaGel 19:1 Denaturing Gel System (National Diagnostics). The conditions used for denaturing PAGE were selected to ensure complete and consistent denaturation of dsDNA using a Mini-PROTEAN ${ }^{\circledR}$ Tetra Vertical Electrophoresis Cell (Bio-Rad): The inner buffer chamber was filled completely with $1 \mathrm{X}$ TBE, but the outer buffer chamber contained enough $1 \mathrm{X}$ TBE to cover only $\sim 1 \mathrm{~cm}$ of the gel plates to reduce heat loss. Urea-PAGE gels were run at $480 \mathrm{~V}$, which is $80 \%$ of the maximum voltage recommended for the Mini-PROTEAN ${ }^{\circledR}$ system. Urea-PAGE gels were stained 
with 1X SYBR Gold (Invitrogen) in 1X TBE for 10 minutes and scanned on an Sapphire ${ }^{\mathrm{TM}}$ Biomolecular Imager (Azure Biosystems) using the $488 \mathrm{~nm} / 518 \mathrm{BP} 22$ setting.

\section{Native PAGE for the analysis of purified DNA}

Purified DNA was assessed using 1 X TBE $8 \%$ polyacrylamide gels prepared using ProtoGel (National Diagnostics) acrylamide. Native PAGE gels were stained with 1X SYBR Gold in 1X TBE for 10 minutes and scanned on a Sapphire ${ }^{\mathrm{TM}}$ Biomolecular Imager using the $488 \mathrm{~nm} / 518 \mathrm{BP} 22$ setting.

\section{Analysis of open complex formation by EMSA}

For Figures $3 \mathrm{~A}$ and $4 \mathrm{~A}$, reactions containing 1X Transcription Buffer $(20 \mathrm{mM}$ Tris- $\mathrm{HCl}(\mathrm{pH} 8.0), 50 \mathrm{mM} \mathrm{KCl}, 1$ mM DTT, $0.1 \mathrm{mM}$ EDTA (pH 8.0)), $0.1 \mathrm{mg} / \mathrm{ml}$ BSA (Invitrogen), $5 \mathrm{nM}$ (Fig. 3A) or $10 \mathrm{nM}$ (Fig. 4A) DNA Template 2 (Table S2), and 0, 0.016, 0.024, 0.032, or $0.048 \mathrm{U} / \mu \mathrm{l}$ E. coli RNAP holoenzyme (NEB) were incubated in a dry bath set to $37^{\circ} \mathrm{C}$ for 15 (Fig. 3A) or 20 (Fig. 4A) minutes. After incubation, $15 \mu$ of sample was mixed with $3 \mu \mathrm{l}$ of 6 X BPB Only Native DNA Loading Dye $(30 \%(\mathrm{v} / \mathrm{v})$ glycerol, $10 \mathrm{mM} \mathrm{Tris-HCl}(\mathrm{pH} 8.0)$, $0.01 \%(\mathrm{w} / \mathrm{v})$ bromophenol blue), loaded on a $0.5 \mathrm{X}$ TBE $5 \%$ polyacrylamide gel that was submerged up to the wells in $0.5 \mathrm{X}$ TBE, and run at $45 \mathrm{~V}$ for $\sim 1.5 \mathrm{hr}$. Gels were stained with 1X SYBR Gold in 0.5X TBE for 10 minutes and scanned on a Sapphire ${ }^{\mathrm{TM}}$ Biomolecular Imager using the $488 \mathrm{~nm} / 518 \mathrm{BP} 22$ setting.

For Figure 4C, open complexes were prepared as described below in the section Purification of TECs by selective photo-elution from streptavidin beads except that NTPs were omitted from the reaction, DNA Templates 6 and 7 (Table S2) were used as the 'Target' and 'Competitor' respectively, and the reactions were performed under low intensity room light instead of $592 \mathrm{~nm}$ light. Reactions were staggered so that all sample handling reached completion simultaneously. $15 \mu \mathrm{l}$ of sample was mixed with $3 \mu \mathrm{l}$ of 6 X BPB Only Native DNA Loading Dye and loaded on a 0.5X TBE 5\% polyacrylamide gel as described above except that the gel was run in a dark room. After the gel had run, it was transferred to a plastic dish containing 0.5X TBE, scanned sequentially on a Sapphire ${ }^{\mathrm{TM}}$ Biomolecular Imager using the $520 \mathrm{~nm} / 565 \mathrm{BP} 24$ and $658 \mathrm{~nm} / 710 \mathrm{BP} 40$ settings, removed from the imager, stained with 1 X SYBR Gold in 0.5X TBE for 10 minutes and scanned again on a Sapphire $^{\mathrm{TM}}$ Biomolecular Imager using the $488 \mathrm{~nm} / 518 \mathrm{BP} 22$ setting.

\section{Internal biotin-TEG sequestration assay}

$10 \mu$ of Dynabeads ${ }^{\mathrm{TM}}$ MyOne ${ }^{\mathrm{TM}}$ Streptavidin $\mathrm{C} 1$ beads per $25 \mu \mathrm{l}$ sample volume were prepared in bulk as described above in Preparation of streptavidin-coated magnetic beads for $P_{R A 1}$ barcoding assays, except that two additional washes were performed using $500 \mu$ of Wash Buffer T (1X Transcription Buffer supplemented with $0.1 \%$ Triton $\mathrm{X}-100$ ) and each sample volume of beads was stored in a $25 \mu$ laliquot in Wash Buffer T.

All $25 \mu$ transcription reactions contained $1 X$ Transcription Buffer, $0.1 \mathrm{mg} / \mathrm{ml}$ BSA, and $5 \mathrm{nM}$ DNA Template 2 (Table S2). NTPs (GE Healthcare) were either omitted or included at $500 \mu \mathrm{M}$ each; E. coli RNAP holoenzyme was either omitted or included at $0.024,0.032$, or $0.048 \mathrm{U} / \mu \mathrm{l}$. At the time of preparation the total reaction volume was $22.5 \mu \mathrm{l}$ due to the omission of $10 \mathrm{X}$ Start Solution (100 mM MgCl, $100 \mu \mathrm{g} / \mathrm{ml}$ rifampicin).

Reactions were placed in a dry bath set to $37^{\circ} \mathrm{C}$ for 15 minutes to form open promoter complexes. $2.5 \mu \mathrm{l}$ of 10X Start Solution was added and transcription was allowed to proceed for 2 minutes during which an aliquot of beads was placed on a magnet stand to remove the Wash Buffer T. After 2 minutes of transcription, the pelleted beads were resuspended using the $25 \mu$ l transcription reaction, placed on a rotator, and incubated at room temperature for 30 minutes. The beads were then returned to the magnet stand and the supernatant was separated from the pellet and added to $125 \mu \mathrm{l}$ of Stop Solution. To recover immobilized DNA, the bead pellet was resuspended in $25 \mu \mathrm{l}$ of $95 \%$ formamide and $10 \mathrm{mM}$ EDTA, heated at $100{ }^{\circ} \mathrm{C}$ for five minutes, placed on a magnet stand, and the supernatant was collected and added to $125 \mu$ of Stop Solution. Reactions were processed for denaturing Urea-PAGE by phenol:chloroform extraction and ethanol precipitation as described above in the section $P_{R A 1}$ barcoding validation assays and resuspended in $16 \mu$ of BPB Only Formamide Loading Dye (90\% (v/v) deionized formamide, 1X Transcription Buffer, 0.01\% (w/v) bromophenol blue). UreaPage was performed as described above in the section Denaturing Urea-PAGE. 


\section{Preparation of streptavidin beads for TEC Purification}

For TEC purification assays, $2.5 \mu \mathrm{l}$ or $5 \mu$ of Dynabeads ${ }^{\mathrm{TM}}$ MyOne ${ }^{\mathrm{TM}}$ Streptavidin $\mathrm{C} 1$ beads per $25 \mu \mathrm{l}$ sample volume were prepared in bulk: Beads were treated with Hydrolysis Buffer, washed with 1 ml High Salt Wash Buffer, and washed with $1 \mathrm{ml}$ Binding Buffer as described above in the section Preparation of streptavidincoated magnetic beads for $P_{R A 1}$ barcoding assays. After removing Binding Buffer, the beads were washed twice with $500 \mu$ l of Wash Buffer T by transferring to a new tube, washing with rotation for 5 minutes at room temperature, and removing the supernatant. After washing the second time with Wash Buffer $\mathrm{T}$, the beads were resuspended to a concentration of $1 \mu \mathrm{g} / \mu \mathrm{l}$ in Wash Buffer T, split into 25 or $50 \mu \mathrm{l}$ aliquots, and stored on ice until use.

\section{Purification of TECs by selective photo-elution from streptavidin beads}

Several protocols for purifying TECs were performed, both for the purpose of protocol development and for assessing the properties of TECs that were prepared in different ways. For simplicity, the final validated protocol is detailed first, and other variations that were performed are then described below with reference to the figure(s) in which each procedure was used. Preparations using the final protocol are shown in Figures 4B, 4D, 5B, S2, S3A, and S3B. All sample handling was performed under low intensity $592 \mathrm{~nm}$ amber light until the $365 \mathrm{~nm}$ UV irradiation step.

For TEC purification 'Target DNA' refers to DNA Template 4 (Table S2), which contains an internal biotin-TEG modification as the RNAP stall site and a PRA1 promoter with 5' PC biotin and C3 Spacer modifications at the 5' end and dU modifications at positions -13 and -30 of the promoter. 'Competitor DNA' refers to DNA Template 5 (Table S2), which contains an internal etheno-dA stall site. For reach transcription reaction, $5 \mu \mathrm{l}$ of $10 \mathrm{mg} / \mathrm{ml}$ Dynabeads $^{\mathrm{TM}}$ MyOne ${ }^{\mathrm{TM}}$ Streptavidin $\mathrm{C} 1$ beads were prepared in advance as described above in the procedure Preparation of streptavidin beads for TEC purification and stored on ice at a concentration of $1 \mu \mathrm{g} / \mu \mathrm{l}$ in $50 \mu \mathrm{l}$ of 1X Wash Buffer T until use. $25 \mu$ in vitro transcription reactions containing 1X Transcription Buffer, $500 \mu \mathrm{M}$ NTPs, $0.1 \mathrm{mg} / \mathrm{ml} \mathrm{BSA}, 10 \mathrm{nM}$ Target DNA, and $0.016 \mathrm{U} / \mu \mathrm{l}$ E. coli RNAP holoenzyme were prepared in a $1.7 \mathrm{ml}$ microcentrifuge tube on ice; at this point the total reaction volume was $20 \mu$ due to the omission of Competitor DNA and 10X Start Solution. Transcription reactions were placed in a dry bath set to $37^{\circ} \mathrm{C}$ for 20 minutes to form open promoter complexes. After $\sim 17$ minutes, a $1.7 \mathrm{ml}$ microcentrifuge tube containing $2.5 \mu \mathrm{l}$ of $150 \mathrm{nM}$ Competitor DNA was placed in the $37^{\circ} \mathrm{C}$ dry bath to pre-warm. After open complexes had formed on Target DNA for 20 minutes, the $20 \mu \mathrm{l}$ transcription reaction was transferred to the tube containing $2.5 \mu \mathrm{l}$ of $150 \mathrm{nM}$ of Competitor DNA; the final concentration of Competitor DNA in the full $25 \mu$ reaction volume was $15 \mathrm{nM}$. The transcription reaction was returned to $37^{\circ} \mathrm{C}$ for an additional 20 minutes so that free RNAP holoenzyme formed open complexes with the Competitor DNA. Dilution Buffer (1X Transcription Buffer supplemented with $10 \mu \mathrm{g} / \mathrm{ml}$ rifampicin and $0.1 \%$ Triton X-100) and streptavidin beads were removed from ice and kept at room temperature at this time. After $\sim 17$ minutes, the streptavidin beads were pipetted to resuspend settled beads. After open complexes had formed on competitor DNA for 20 minutes, single-round transcription was initiated by adding $2.5 \mu \mathrm{l}$ of freshly prepared $10 \mathrm{X}$ Start Solution, incubated at $37^{\circ} \mathrm{C}$ for 2 minutes, and gently diluted into $425 \mu \mathrm{l}$ of room temperature Dilution Buffer by pipetting. Dilution Buffer contains rifampicin to maintain single-round transcription conditions during bead binding. The purpose of diluting the reaction was to minimize the occurrence of bead cross-linking by DNA templates in which both biotin modifications were exposed; when bead binding was performed using a sample volume of $25 \mu \mathrm{l}$, substantial bead clumping was observed. No observable clumping occurred when the binding reaction was diluted 10 - or 20 -fold. The diluted $450 \mu \mathrm{l}$ transcription reaction was then gently mixed with $50 \mu \mathrm{l}$ of $1 \mu \mathrm{g} / \mu \mathrm{l}$ streptavidin beads by pipetting. The bead binding reaction was incubated in the dark at room temperature with rotation for 1 hour. After 1 hour, the bead binding mixture was spun briefly in a Labnet Prism mini centrifuge (Labnet International) by flicking the switch on and off so that liquid was removed from the tube cap. The $1.7 \mathrm{ml}$ tube containing the bead binding reaction was placed on a magnet stand for at least 2 minutes to pellet the streptavidin beads on the tube wall, and the supernatant was carefully removed; this supernatant, which contains any reaction components that did not bind the beads including virtually all Competitor DNA, is referred to as fraction $\mathrm{S} 1$. The $1.7 \mathrm{ml}$ tube containing the beads was removed from the magnet stand, the beads were gently resuspended in $500 \mu l$ of Wash Buffer TM (1X Transcription Buffer supplemented with $1 \mathrm{mM} \mathrm{MgCl}_{2}$ and $0.1 \%$ Triton $\mathrm{X}-100$ ) by pipetting, and the sample was returned to the magnet stand for two minutes to pellet the streptavidin beads before removing the supernatant; this supernatant, which contains residual reactions components, is referred to as fraction $\mathrm{W}$. The 
streptavidin beads were then gently resuspended in $25 \mu$ of Wash Buffer TM by pipetting so that the bead concentration was $2 \mu \mathrm{g} / \mu \mathrm{l}$, and placed in a custom-built $365 \mathrm{~nm}$ LED irradiator for $1.7 \mathrm{ml}$ microcentrifuge tubes (Fig. S1, see Assembly and validation of a $365 \mathrm{~nm}$ microcentrifuge tube irradiator below for details) and exposed to $\sim 10 \mathrm{~mW} / \mathrm{cm}^{2} 365 \mathrm{~nm}$ UV light from four directions for 5 minutes. After irradiation, the bead mixture was returned to the magnet stand for 1 minute before collecting the supernatant; the pelleted beads, which contain DNA without a TEC and any TECs that were not eluted by $365 \mathrm{~nm}$ UV irradiation, are referred to as fraction $\mathrm{P}$. The collected supernatant, which contains purified TECs, is referred to as fraction S2.

Several variations on this protocol were performed. In the proof-of-principle experiment in Figure 3D, the transcription reaction included $5 \mathrm{nM}$ Target DNA and $0.024 \mathrm{U} / \mu \mathrm{l}$ RNAP holoenzyme, Competitor DNA was not included, half the amount of streptavidin beads ( $25 \mu \mathrm{g}$ vs. $50 \mu \mathrm{g})$ were used, and the volumes used for the bead binding and wash steps were halved $(250 \mu \mathrm{l}$ vs. $500 \mu \mathrm{l})$. In Figures 4B, 5B, and S2, TECs were prepared with variable RNAP, Target DNA, and Competitor DNA concentrations. The conditions used for each preparation are indicated by the gel annotations. All samples that used $5 \mathrm{nM}$ template were prepared with the protocol modifications described for the TEC preparation in Figure 3D.

\section{Analysis of TEC purification fractions by denaturing PAGE}

TEC purification fractions were prepared for denaturing PAGE as follows: Fractions S1 and W were mixed with $5 \mu \mathrm{l}$ of $0.5 \mathrm{M}$ EDTA ( $\mathrm{pH}$ 8.0). To recover immobilized DNA in Fraction $\mathrm{P}$, the bead pellet was resuspended in $25 \mu \mathrm{l}$ of $95 \%$ formamide and $10 \mathrm{mM}$ EDTA, heated at $100{ }^{\circ} \mathrm{C}$ for five minutes, placed on a magnet stand, and the supernatant was collected and mixed with $125 \mu \mathrm{l}$ of Stop Solution. Fraction S2 was mixed with $125 \mu \mathrm{l}$ of Stop Solution. The volumes of Fractions $\mathrm{P}$ and $\mathrm{S} 2$ were then raised to match the volume of Fractions $\mathrm{S} 1$ and W $(250 \mu \mathrm{l}$ in Fig. 3D or $500 \mu \mathrm{l}$ in Fig. 4D) by adding 1X Transcription Buffer. The fractions were extracted by adding an equal volume of Tris ( $\mathrm{pH} 8)$ buffered phenol:chloroform:isoamyl alcohol (25:24:1, v/v), mixing by vortexing and inversion, and centrifuging at $18,500 \times \mathrm{g}$ and $4{ }^{\circ} \mathrm{C}$ for five minutes. The aqueous phase was collected and transferred to a new tube. When the volume of the extracted samples was $250 \mu \mathrm{l}$, nucleic acids were precipitated by adding $25 \mu \mathrm{l} 3 \mathrm{M} \mathrm{NaOAc}(\mathrm{pH} 5.5), 750 \mu \mathrm{l} 100 \%$ ethanol, and $1.5 \mu \mathrm{l} \mathrm{GlycoBlue}^{\mathrm{TM}}$ Coprecipitant to each sample and chilling at $-70{ }^{\circ} \mathrm{C}$ for 30 minutes. When the volume of the extracted samples was $500 \mu \mathrm{l}$, nucleic acids were precipitated by adding $50 \mu \mathrm{l} 3 \mathrm{M} \mathrm{NaOAc}(\mathrm{pH}$ 5.5), $350 \mu \mathrm{l} 100 \%$ isopropanol, and $1.5 \mu \mathrm{l} \mathrm{GlycoBlue}{ }^{\mathrm{TM}}$ Coprecipitant to each sample and chilling on ice for 30 minutes. The samples were centrifuged at $18,500 \times \mathrm{g}$ and $4{ }^{\circ} \mathrm{C}$ for 30 minutes and the supernatant was removed. When isopropanol precipitations were performed, the pellet was washed once by adding $1 \mathrm{ml}$ of cold $70 \%(\mathrm{v} / \mathrm{v})$ ethanol, inverting the tube several times, centrifuging at $18,500 \mathrm{xg}$ and $4{ }^{\circ} \mathrm{C}$ for 2 minutes, and removing the supernatant. After removing residual ethanol, the pellet was dissolved in $16 \mu \mathrm{l}$ of BPB Only Formamide Loading Dye and the entire sample was loaded on the gel. Urea-Page was performed as described above in the section Denaturing Urea-PAGE.

\section{Analysis of purified TECs by EMSA}

After purifying TECs as described above, $15 \mu$ of fraction S2, which contains purified TECs, was gently mixed with $3 \mu \mathrm{l}$ of 6 X BPB Only Native DNA Loading Dye. Samples were loaded on a 0.5X TBE 5\% polyacrylamide gel prepared using ProtoGel acrylamide. Gels were immersed up to the wells in 0.5X TBE to minimize heating and run at room temperature at $45 \mathrm{~V}$ for approximately 1.5 hours before being stained using $1 X$ SYBR Gold in 0.5X TBE and scanned on a Sapphire Biomolecular imager using the $488 \mathrm{nM} / 518 \mathrm{BP} 22$ setting.

\section{USER $^{\circledR}$ protection assay}

For the USER ${ }^{\circledR}$ protection assay, TECs were prepared in parallel using the final validated protocol (10 nM Target DNA (DNA Template 4 in Table S2), $0.016 \mathrm{U} / \mu \mathrm{l}$ RNAP holoenzyme, and $15 \mathrm{nM}$ Competitor DNA (DNA Template 5 in Table S2) and conditions that mostly yielded a slow-migrating product when assessed by EMSA (5 nM Target DNA, $0.024 \mathrm{U} / \mu \mathrm{l}$ RNAP holoenzyme, and no Competitor DNA). One modification was made to the TEC purification protocol: Wash Buffer TM was supplemented with $10 \mu \mathrm{g} / \mathrm{ml}$ rifampicin so that the TEC preparations contained 1X Transcription Buffer, $1 \mathrm{mM} \mathrm{MgCl}_{2}$, and $10 \mu \mathrm{g} / \mathrm{ml}$ rifampicin; this prevents activity by any remaining open complexes during the USER ${ }^{\circledR}$ digestion, which requires ATP and magnesium. During the bead binding step of the TEC purification protocol, several control reactions were prepared. All $25 \mu$ control 
reactions contained 1X Transcription Buffer, $0.1 \mathrm{mg} / \mathrm{ml} \mathrm{BSA}$, and $5 \mathrm{nM}$ DNA Template 4 (Table S2); the +RNAP control reaction contained $0.024 \mathrm{U} / \mu \mathrm{l}$ RNAP holoenzyme, which saturates the PRA1 promoter with open complexes (Fig. 3A). At the time of preparation, control reactions were $20 \mu$ ldue to the omission of $10 \mathrm{X}$ rifampicin and 10X T4 DNA Ligase Buffer.

Upon elution from streptavidin beads, $25 \mu$ l aliquots of purified TECs were mixed with $2.5 \mu$ of 10X T4 DNA Ligase Buffer and either placed directly in a dry bath set to $37^{\circ} \mathrm{C}$ (-USER ${ }^{\circledR}$ samples) or mixed with $0.5 \mu$ of Thermolabile USER ${ }^{\circledR}$ II Enzyme before being placed at $37^{\circ} \mathrm{C}$ (+USER ${ }^{\circledR}$ samples). In both cases, purified TECs were incubated at $37^{\circ} \mathrm{C}$ for 30 minutes, which far exceeds the time required for complete USER ${ }^{\circledR}$ digestion $(<5$ minutes). Control reactions were incubated at $37^{\circ} \mathrm{C}$ for 15 minutes to form open complexes. Rifampicin was added to $10 \mu \mathrm{g} / \mathrm{ml}$ and the reactions were incubated at $37^{\circ} \mathrm{C}$ for 5 additional minutes before the addition of 2.5 $\mu$ l of 10X T4 DNA Ligase Buffer and, in the case of the +USER ${ }^{\circledR}$ samples, $0.5 \mu$ of Thermolabile USER ${ }^{\circledR}$ II Enzyme. The control reactions were incubated $37^{\circ} \mathrm{C}$ for 30 minutes. USER ${ }^{\circledR}$ digestion was stopped by the addition of $125 \mu \mathrm{l}$ of Stop Solution, and the samples were processed for denaturing PAGE by phenol:chloroform extraction and ethanol precipitation as described in the section $P_{R A 1}$ barcoding validation assays, resuspended in $16 \mu$ of BPB Only Formamide Loading Dye and the entire sample was used for denaturing PAGE.

\section{TEC degradation assay}

TECs were purified as described above; 1 reaction volume was removed from the in vitro transcription master mix before the addition of $E$. coli RNAP holoenzyme and kept on ice as a DNA only control. Purified TECs were split into $25 \mu \mathrm{l}$ aliquots and kept at room temperature. When included in the reaction, $1 \mu \mathrm{l}$ of Thermolabile Proteinase $\mathrm{K}$ was added and mixed with the sample immediately before the sample was placed at $37^{\circ} \mathrm{C}$. All samples were incubated at $37^{\circ} \mathrm{C}$ for 30 minutes, and one sample was heat inactivated by incubating at $65^{\circ} \mathrm{C}$ in a thermal cycler for 10 minutes. The time course was structured so that all sample handling reached completion simultaneously. $15 \mu$ of each sample was gently mixed with $3 \mu \mathrm{l}$ XX BPB Only Native DNA Loading Dye and assessed by EMSA as described above in the section Analysis of purified TECs by EMSA.

\section{$P_{\mathrm{RA} 1}$ barcoding of DNA from purified TECs}

TECs were prepared as described above, except that $50 \mu \mathrm{l}$ transcription reactions were used, and the volume of every step was adjusted accordingly. Purified TECs were pooled. A $15 \mu \mathrm{l}$ aliquot was removed and assessed by EMSA as described above in the section Analysis of purified TECs by EMSA, and a $25 \mu \mathrm{l}$ 'Input' fraction was mixed with $125 \mu \mathrm{l}$ of Stop Solution, phenol:chloform extracted and set up for ethanol precipitation as described above in the section $P_{R A 1}$ barcoding validation assays. All subsequent incubations were performed in a thermal cycler. $150 \mu \mathrm{l}$ of the remaining sample was mixed with $6 \mu \mathrm{l}(1 \mu \mathrm{l}$ per sample volume) of Thermolabile Proteinase K (NEB), incubated at $37^{\circ} \mathrm{C}$ for 30 minutes, and then at $65^{\circ} \mathrm{C}$ for 20 minutes. $3 \mu \mathrm{l}$ $\left(0.5 \mu \mathrm{l}\right.$ per sample volume) of RNase $\mathrm{I}_{\mathrm{f}}$ (NEB) was added and the sample was incubated at $37^{\circ} \mathrm{C}$ for 15 minutes, and then at $70{ }^{\circ} \mathrm{C}$ for 20 minutes. Together these steps degraded RNAP and RNA, and the sample was stored at $-20^{\circ} \mathrm{C}$ overnight. The next day, $26.5 \mu \mathrm{l}$ was removed and mixed with $125 \mu$ of Stop Solution. The remaining sample was mixed with $12.5 \mu \mathrm{l}(2.5 \mu \mathrm{l}$ per sample volume) of 10X T4 DNA ligase Buffer and 2.5 $\mu \mathrm{l}\left(0.5 \mu \mathrm{l}\right.$ per sample volume) of Thermolablie USER ${ }^{\circledR}$ II Enzyme and processed exactly as described above in the section $P_{R A 1}$ barcoding validation assays through the Klenow Fragment primer extension step. After each enzymatic processing step a reaction fraction (with volume adjusted for added components) was mixed with $125 \mu \mathrm{l}$ of Stop Solution. All intermediate fractions were phenol:chloroform extracted and ethanol precipitated as described above in the section $P_{R A 1}$ barcoding validation assays, and the pellet was resuspended in $16 \mu l$ of BPB Only Formamide Loading Dye for denaturing PAGE. After all intermediate fractions were collected, this procedure yielded two reaction volumes of bead-immobilized barcoded DNA. The beads were washed once with $1 \mathrm{ml}$ of $10 \mathrm{mM}$ Tris- $\mathrm{HCl}(\mathrm{pH} 8.0)$ supplemented with $0.05 \%$ Triton X-100, and resuspended in $25 \mu \mathrm{l}$ of this same buffer for storage at $-20^{\circ} \mathrm{C}$.

PCR of the barcoded DNA was performed in $25 \mu$ reactions in $200 \mu$ thin-walled PCR tubes containing $1 \mathrm{X}$ Q5 ${ }^{\circledR}$ Buffer, 1X Q5 ${ }^{\circledR}$ GC Enhancer, $0.2 \mathrm{mM}$ dNTPs, $0.25 \mu \mathrm{M}$ primer RPI1 (Table S1), $0.25 \mu \mathrm{M}$ primer dRP1_NoMod.R (Table S1), $2 \mu$ l bead-immobilized barcoded DNA, and $0.02 \mathrm{U} / \mu \mathrm{l} 5^{\circledR}$ High-Fidelity DNA 
Polymerase (NEB). Reactions were amplified using the thermal cycling program: $98{ }^{\circ} \mathrm{C}$ for $30 \mathrm{~s}$, $\left[98^{\circ} \mathrm{C}\right.$ for 10 $\mathrm{s}, 69^{\circ} \mathrm{C}$ for $20 \mathrm{~s}, 72^{\circ} \mathrm{C}$ for $20 \mathrm{~s}$ ] $\times \mathrm{N}$ cycles (where $\mathrm{N}=3,4$, or 5 cycles as indicated in Fig. S3B), hold at 12 ${ }^{\circ} \mathrm{C}$. After amplification, reactions were transferred to $1.7 \mathrm{ml}$ microcentrifuge tubes and placed on a magnet stand to pellet the beads. The supernatant was collected, and $5 \mu \mathrm{l}$ of supernatant was mixed with $1 \mu \mathrm{l}$ of $6 \mathrm{X}$ BPB Only SDS DNA Loading Dye (30\% (v/v) glycerol, $10 \mathrm{mM}$ Tris-HCl (pH 8.0), 0.48\% (w/v) SDS, 0.01\% (w/v) bromophenol blue) for electrophoresis as described above in the section Native PAGE for the analysis of purified DNA.

\section{Assembly and validation of a $365 \mathrm{~nm}$ microcentrifuge tube irradiator.}

To enable efficient $365 \mathrm{~nm}$ UV-induced cleavage of 5' PC biotin in a magnetic bead mixture (which can reduce photocleavage efficiency due to light scattering), a custom $1.7 \mathrm{ml}$ microcentrifuge tube irradiator was assembled using $365 \mathrm{~nm}$ realUV ${ }^{\mathrm{TM}}$ LED Light Strips (Waveform Lighting, Product \# 7021.65). The irradiator was designed such that each tube was irradiated by four individual segments of the LED light strip (3 LEDs each, $\sim 10 \mathrm{~mW} / \mathrm{cm}^{2}$ from $\sim 1 \mathrm{~cm}$ away from the tube) simultaneously. The irradiator was constructed using the 365 nm LED strips above, LED Strip to Strip Solderless Connectors (Waveform Lighting, Product \# 3071), a Female DC Barrel Jack Plug Adapter (Waveform Lighting, Product \# 7094), the tube-holder insert from a Beta Box for $1.5 \mathrm{ml}$ microcentrifuge tubes (Fisher Scientific, Cat \# 12-009-14), a Desktop AC Adapter (Mean Well, Cat \# GST60A12-P1J), and a NEMA 5-15P to IEC320C13 Universal Power Cord (C2G, Product \#03129). 3M 12mm VHB Double Sided Foam Adhesive Tape 5952 and hardware including corner brackets, machine screws, washers, and T plates were used to mount the LED strips to the tube-holder insert. A UVA/B light meter calibrated to $365 \mathrm{~nm}$ (General, Item \# UV513AB) was used to assess $365 \mathrm{~nm}$ UV intensity.

To assess $365 \mathrm{~nm}$ UV-induced cleavage of 5' PC biotin, $25 \mu \mathrm{l}$ reactions containing $1 \mathrm{X}$ Transcription Buffer, 0.1 $\mathrm{mg} / \mathrm{ml}$ BSA, and $5 \mathrm{nM}$ primer PRA1_2dU_PCbio.F (Table S1) were mixed with streptavidin coated magnetic beads (prepared as described above in Preparation of streptavidin beads for TEC Purification) to $2 \mu \mathrm{g} / \mu \mathrm{l}$ or 1 $\mu \mathrm{g} / \mu \mathrm{l}$ and incubated at room temperature with rotation for 30 minutes. The supernatant from this binding reaction, which contains any oligonucleotide that did not bind the beads, was discarded and the beads were resuspended in $25 \mu \mathrm{l}$ of Wash Buffer T and exposed to $365 \mathrm{~nm}$ UV light at $10 \mathrm{~mW} / \mathrm{cm}^{2}$ from four directions for five minutes. The samples were placed on a magnet stand and the supernatant was collected in $125 \mu$ of Stop Solution. To recover immobilized DNA, the bead pellet was resuspended in $25 \mu \mathrm{l}$ of $95 \%$ formamide and 10 $\mathrm{mM}$ EDTA, heated at $100{ }^{\circ} \mathrm{C}$ for five minutes, placed on a magnet stand, and the supernatant was collected and added to $125 \mu \mathrm{l}$ of Stop Solution. Reactions were processed for denaturing Urea-PAGE by phenol:chloroform extraction and ethanol precipitation as described above in the section $P_{R A 1}$ barcoding validation assays and resuspended in $7 \mu$ I BPB Only Formamide Loading Dye. Urea-Page was performed as described above in the section Denaturing Urea-PAGE.

\section{Quantification}

Quantification of band intensity was performed using ImageJ 1.51s by plotting each lane, drawing a line at the base of each peak to subtract background, and determining the area of the closed peak. Because EMSA bands had long trails at the edge of the lane that could overlap for multiple bands, TEC purity was calculated using the internal width of the lane that did not include the trails at the edge.

\section{Reproducibility of the methods}

Key procedures for TEC purification and $\mathrm{P}_{\mathrm{RA} 1}$ barcoding were performed at least five times during protocol development and as controls for validation assays, some of which are presented here. Of particular importance, EMSAs of four independent TEC preparations that were purified using the final validated protocol (detailed below under Purification of TECs by selective photo-elution from streptavidin beads) can be found in Figures $4 \mathrm{~B}, \mathrm{~S} 2, \mathrm{~S} 3 \mathrm{~A}$, and S3B, and stepwise verification of the $\mathrm{P}_{\mathrm{RA} 1}$ barcoding procedure is shown in Figures $2 \mathrm{C}, 2 \mathrm{D}, 2 \mathrm{E}$, and S3B.

\section{Data availability}

All data are contained in the manuscript as plotted values or representative gels. Source files in .tif format are available from the corresponding author (E.J.S.) upon request. 


\section{Supporting information}

This article contains supporting information.

\section{Acknowledgements}

I am grateful to J.B. Lucks (Northwestern University) and J.T. Lis (Cornell University) for allowing me to conduct preliminary experiments for this work in their laboratories.

\section{Author Contributions}

E.J.S. is responsible for all aspects of this work.

\section{Funding}

This work was supported by startup funding from the University at Buffalo (to E.J.S.), an Arnold O. Beckman postdoctoral fellowship (to E.J.S.), and a Cornell University Genomics Innovation Hub Seed Grant (to J.T.L. and E.J.S.).

\section{Conflict of Interest}

The author declares that he has no conflicts of interest with the contents of this article.

\section{Abbreviations}

The abbreviations used are: RNAP, RNA polymerase; TEC, transcription elongation complex; TEG, triethylene glycol; PC, photocleavable; dU, deoxyuridine; USER, uracil specific excision reagent; etheno-dA, $1, \mathrm{~N}^{6}$-etheno2'-deoxyadenosine; P, pellet; S, supernatant.

\section{$\underline{\text { References }}$}

1. Cech, T. R., and Steitz, J. A. (2014) The noncoding RNA revolution-trashing old rules to forge new ones. Cell 157, 77-94

2. Ganser, L. R., Kelly, M. L., Herschlag, D., and Al-Hashimi, H. M. (2019) The roles of structural dynamics in the cellular functions of RNAs. Nat Rev Mol Cell Biol 20, 474-489

3. Pan, T., and Sosnick, T. (2006) RNA folding during transcription. Annu Rev Biophys Biomol Struct 35, 161-175

4. Lai, D., Proctor, J. R., and Meyer, I. M. (2013) On the importance of cotranscriptional RNA structure formation. RNA 19, 1461-1473

5. Denny, S. K., and Greenleaf, W. J. (2019) Linking RNA Sequence, Structure, and Function on Massively Parallel High-Throughput Sequencers. Cold Spring Harb Perspect Biol 11

6. Tome, J. M., Ozer, A., Pagano, J. M., Gheba, D., Schroth, G. P., and Lis, J. T. (2014) Comprehensive analysis of RNA-protein interactions by high-throughput sequencing-RNA affinity profiling. Nat Methods 11, 683-688

7. Buenrostro, J. D., Araya, C. L., Chircus, L. M., Layton, C. J., Chang, H. Y., Snyder, M. P., and Greenleaf, W. J. (2014) Quantitative analysis of RNA-protein interactions on a massively parallel array reveals biophysical and evolutionary landscapes. Nat Biotechnol 32, 562-568

8. Heilman-Miller, S. L., and Woodson, S. A. (2003) Effect of transcription on folding of the Tetrahymena ribozyme. RNA 9, 722-733

9. Watters, K. E., Strobel, E. J., Yu, A. M., Lis, J. T., and Lucks, J. B. (2016) Cotranscriptional folding of a riboswitch at nucleotide resolution. Nat Struct Mol Biol 23, 1124-1131

10. Yu, A. M., Gasper, P. M., Cheng, L., Lai, L. B., Kaur, S., Gopalan, V., Chen, A. A., and Lucks, J. B. (2021) Computationally reconstructing cotranscriptional RNA folding from experimental data reveals rearrangement of non-native folding intermediates. Mol Cell 81, 870-883 e810

11. Andreasson, J. O. L., Savinov, A., Block, S. M., and Greenleaf, W. J. (2020) Comprehensive sequenceto-function mapping of cofactor-dependent RNA catalysis in the glmS ribozyme. Nat Commun 11, 1663

12. Hein, P. P., Kolb, K. E., Windgassen, T., Bellecourt, M. J., Darst, S. A., Mooney, R. A., and Landick, R. (2014) RNA polymerase pausing and nascent-RNA structure formation are linked through clampdomain movement. Nat Struct Mol Biol 21, 794-802 
13. Widom, J. R., Rai, V., Rohlman, C. E., and Walter, N. G. (2019) Versatile transcription control based on reversible dCas9 binding. RNA 25, 1457-1469

14. Zhang, J., and Landick, R. (2016) A Two-Way Street: Regulatory Interplay between RNA Polymerase and Nascent RNA Structure. Trends Biochem Sci 41, 293-310

15. She, R., Chakravarty, A. K., Layton, C. J., Chircus, L. M., Andreasson, J. O., Damaraju, N., McMahon, P. L., Buenrostro, J. D., Jarosz, D. F., and Greenleaf, W. J. (2017) Comprehensive and quantitative mapping of RNA-protein interactions across a transcribed eukaryotic genome. Proc Natl Acad Sci U S A 114, 3619-3624

16. Denny, S. K., Bisaria, N., Yesselman, J. D., Das, R., Herschlag, D., and Greenleaf, W. J. (2018) HighThroughput Investigation of Diverse Junction Elements in RNA Tertiary Folding. Cell 174, 377-390 e320

17. Jarmoskaite, I., Denny, S. K., Vaidyanathan, P. P., Becker, W. R., Andreasson, J. O. L., Layton, C. J., Kappel, K., Shivashankar, V., Sreenivasan, R., Das, R., Greenleaf, W. J., and Herschlag, D. (2019) A Quantitative and Predictive Model for RNA Binding by Human Pumilio Proteins. Mol Cell 74, 966-981 e918

18. Becker, W. R., Ober-Reynolds, B., Jouravleva, K., Jolly, S. M., Zamore, P. D., and Greenleaf, W. J. (2019) High-Throughput Analysis Reveals Rules for Target RNA Binding and Cleavage by AGO2. Mol Cell 75, 741-755 e711

19. Yesselman, J. D., Denny, S. K., Bisaria, N., Herschlag, D., Greenleaf, W. J., and Das, R. (2019) Sequence-dependent RNA helix conformational preferences predictably impact tertiary structure formation. Proc Natl Acad Sci U S A 116, 16847-16855

20. Wu, M. J., Andreasson, J. O. L., Kladwang, W., Greenleaf, W., and Das, R. (2019) Automated Design of Diverse Stand-Alone Riboswitches. ACS Synth Biol 8, 1838-1846

21. Strobel, E. J., Yu, A. M., and Lucks, J. B. (2018) High-throughput determination of RNA structures. Nat Rev Genet 19, 615-634

22. Ozer, A., Pagano, J. M., and Lis, J. T. (2014) New Technologies Provide Quantum Changes in the Scale, Speed, and Success of SELEX Methods and Aptamer Characterization. Mol Ther Nucleic Acids 3, e183

23. Wang, T., Chen, C., Larcher, L. M., Barrero, R. A., and Veedu, R. N. (2019) Three decades of nucleic acid aptamer technologies: Lessons learned, progress and opportunities on aptamer development. Biotechnol Adv 37, 28-50

24. Strobel, E. J., Lis, J. T., and Lucks, J. B. (2020) Chemical roadblocking of DNA transcription for nascent RNA display. J Biol Chem 295, 6401-6412

25. Bitinaite, J., Rubino, M., Varma, K. H., Schildkraut, I., Vaisvila, R., and Vaiskunaite, R. (2007) USER friendly DNA engineering and cloning method by uracil excision. Nucleic Acids Res 35, 1992-2002

26. Lindahl, T., Ljungquist, S., Siegert, W., Nyberg, B., and Sperens, B. (1977) DNA N-glycosidases: properties of uracil-DNA glycosidase from Escherichia coli. J Biol Chem 252, 3286-3294

27. Longo, M. C., Berninger, M. S., and Hartley, J. L. (1990) Use of uracil DNA glycosylase to control carryover contamination in polymerase chain reactions. Gene 93, 125-128

28. Dizdaroglu, M., Laval, J., and Boiteux, S. (1993) Substrate specificity of the Escherichia coli endonuclease III: excision of thymine- and cytosine-derived lesions in DNA produced by radiationgenerated free radicals. Biochemistry 32, 12105-12111

29. Hatahet, Z., Kow, Y. W., Purmal, A. A., Cunningham, R. P., and Wallace, S. S. (1994) New substrates for old enzymes. 5-Hydroxy-2'-deoxycytidine and 5-hydroxy-2'-deoxyuridine are substrates for Escherichia coli endonuclease III and formamidopyrimidine DNA N-glycosylase, while 5-hydroxy-2'deoxyuridine is a substrate for uracil DNA N-glycosylase. J Biol Chem 269, 18814-18820

30. Henderson, K. L., Felth, L. C., Molzahn, C. M., Shkel, I., Wang, S., Chhabra, M., Ruff, E. F., Bieter, L., Kraft, J. E., and Record, M. T., Jr. (2017) Mechanism of transcription initiation and promoter escape by E. coli RNA polymerase. Proc Natl Acad Sci U S A 114, E3032-E3040

31. Estrem, S. T., Ross, W., Gaal, T., Chen, Z. W., Niu, W., Ebright, R. H., and Gourse, R. L. (1999) Bacterial promoter architecture: subsite structure of UP elements and interactions with the carboxyterminal domain of the RNA polymerase alpha subunit. Genes Dev 13, 2134-2147

32. Holz, K., Pavlic, A., Lietard, J., and Somoza, M. M. (2019) Specificity and Efficiency of the Uracil DNA Glycosylase-Mediated Strand Cleavage Surveyed on Large Sequence Libraries. Sci Rep 9, 17822 
33. Boudsocq, F., Iwai, S., Hanaoka, F., and Woodgate, R. (2001) Sulfolobus solfataricus P2 DNA polymerase IV (Dpo4): an archaeal DinB-like DNA polymerase with lesion-bypass properties akin to eukaryotic poleta. Nucleic Acids Res 29, 4607-4616

34. Fiala, K. A., Brown, J. A., Ling, H., Kshetry, A. K., Zhang, J., Taylor, J. S., Yang, W., and Suo, Z. (2007) Mechanism of template-independent nucleotide incorporation catalyzed by a template-dependent DNA polymerase. J Mol Biol 365, 590-602

35. Johnston, D. E., and McClure, W. R. (1976) Abortive initiation of in vitro RNA synthesis on bacteriophage $\lambda D N A$, Cold Spring Harbor Laboratory Press, Cold Spring Harbor, NY

36. Carpousis, A. J., and Gralla, J. D. (1980) Cycling of ribonucleic acid polymerase to produce oligonucleotides during initiation in vitro at the lac UV5 promoter. Biochemistry 19, 3245-3253

37. Kubori, T., and Shimamoto, N. (1996) A branched pathway in the early stage of transcription by Escherichia coli RNA polymerase. J Mol Biol 256, 449-457

38. Olejnik, J., Sonar, S., Krzymanska-Olejnik, E., and Rothschild, K. J. (1995) Photocleavable biotin derivatives: a versatile approach for the isolation of biomolecules. Proc Natl Acad Sci U S A 92, 75907594

39. Artsimovitch, I., and Henkin, T. M. (2009) In vitro approaches to analysis of transcription termination. Methods 47, 37-43

40. Ramanathan, M., Porter, D. F., and Khavari, P. A. (2019) Methods to study RNA-protein interactions. Nat Methods 16, 225-234

41. McCown, P. J., Corbino, K. A., Stav, S., Sherlock, M. E., and Breaker, R. R. (2017) Riboswitch diversity and distribution. RNA 23, 995-1011

42. Guil, S., and Esteller, M. (2015) RNA-RNA interactions in gene regulation: the coding and noncoding players. Trends Biochem Sci 40, 248-256

43. Lambert, N., Robertson, A., Jangi, M., McGeary, S., Sharp, P. A., and Burge, C. B. (2014) RNA Bind-nSeq: quantitative assessment of the sequence and structural binding specificity of RNA binding proteins. Mol Cell 54, 887-900

44. Strobel, E. J., Watters, K. E., Nedialkov, Y., Artsimovitch, I., and Lucks, J. B. (2017) Distributed biotinstreptavidin transcription roadblocks for mapping cotranscriptional RNA folding. Nucleic Acids Res $\mathbf{4 5}$, e109

45. Pupov, D., Ignatov, A., Agapov, A., and Kulbachinskiy, A. (2019) Distinct effects of DNA lesions on RNA synthesis by Escherichia coli RNA polymerase. Biochem Biophys Res Commun 510, 122-127

46. Daube, S. S., and von Hippel, P. H. (1992) Functional transcription elongation complexes from synthetic RNA-DNA bubble duplexes. Science 258, 1320-1324

47. Sidorenkov, I., Komissarova, N., and Kashlev, M. (1998) Crucial role of the RNA:DNA hybrid in the processivity of transcription. Mol Cell 2, 55-64

48. Kwak, H., Fuda, N. J., Core, L. J., and Lis, J. T. (2013) Precise maps of RNA polymerase reveal how promoters direct initiation and pausing. Science 339, 950-953

49. Mahat, D. B., Kwak, H., Booth, G. T., Jonkers, I. H., Danko, C. G., Patel, R. K., Waters, C. T., Munson, K., Core, L. J., and Lis, J. T. (2016) Base-pair-resolution genome-wide mapping of active RNA polymerases using precision nuclear run-on (PRO-seq). Nat Protoc 11, 1455-1476

50. Bae, B., Feklistov, A., Lass-Napiorkowska, A., Landick, R., and Darst, S. A. (2015) Structure of a bacterial RNA polymerase holoenzyme open promoter complex. Elife $\mathbf{4}$ 


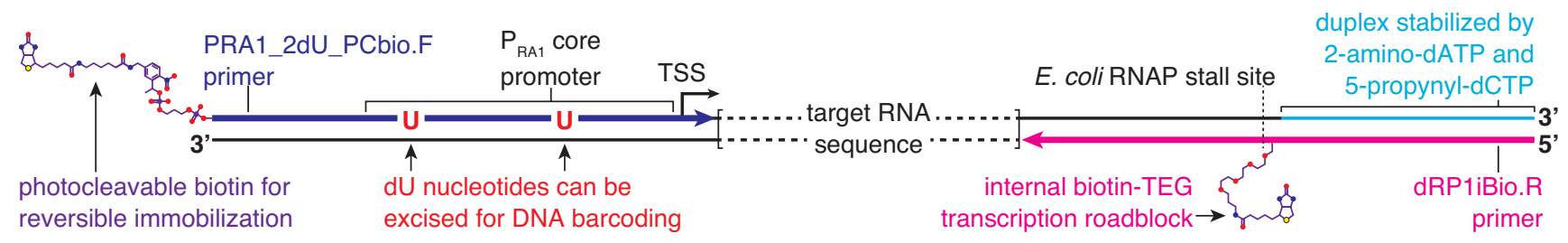

Figure 1. Layout of chemically modified constant regions used in TEC Display. TEC Display uses two chemically modified constant DNA sequences for integrated TEC purification and DNA barcoding procedures. An internal biotin-TEG modification, which functions as an E. coli RNAP stall site and an attachment point during TEC purification and DNA barcoding, is introduced by the dRP1iBio.R primer. Thermostabilityenhancing 2-amino-dATP and 5-propynyl-dCTP nucleotides are added to the non-transcribed DNA strand downstream of the internal biotin-TEG modification during the translesion synthesis step of DNA template preparation to stabilize this 29 bp region. The PRA1_2dU_PCbio.F primer introduces a 5' PC biotin modification for reversible DNA immobilization during TEC purification along with two dU nucleotides that are excisable to facilitate DNA barcoding. Oligonucleotide sequences, including information about required purifications, are available in Table S1. 


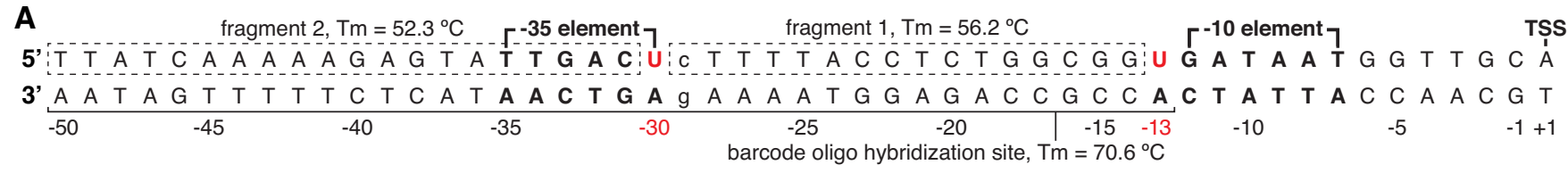

\section{B}

\section{PRA1 contains} two dU nucleotides

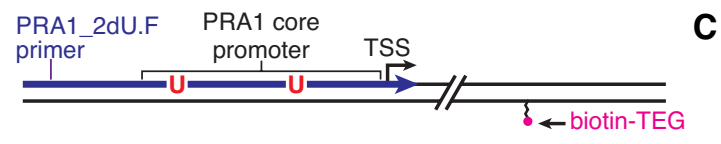

digest PRA1 NT DNA strand w/ USER

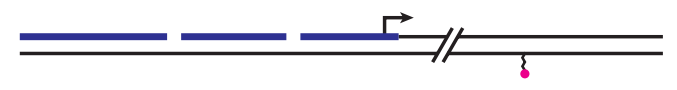

competitively anneal and ligate barcode oligonucleotide

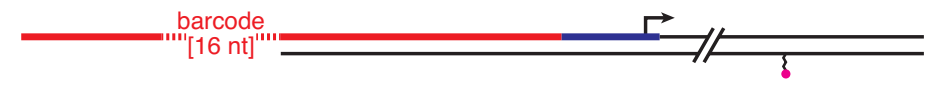

immobilize and wash to eliminate excess barcode oligonucleotide

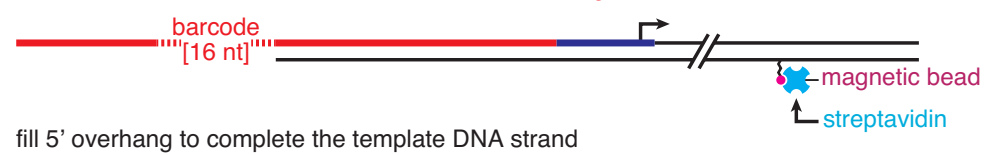

_, barcode

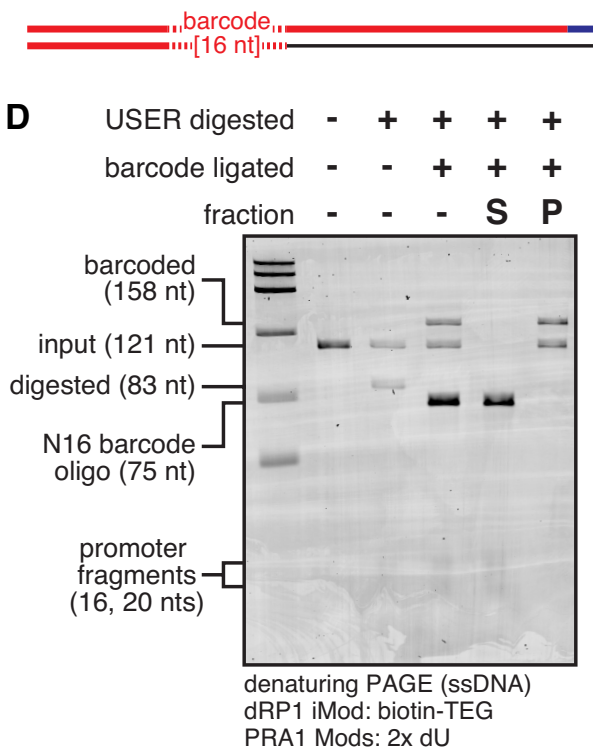

C

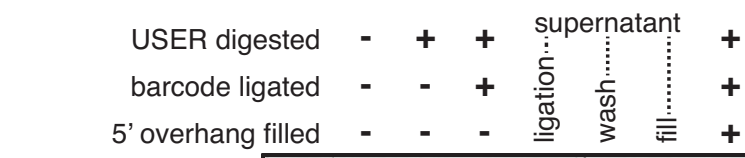

Figure 2. One-pot $\sigma^{70}$ promoter barcoding. (A) Overview of the $P_{\text {RA1 }}$ promoter. Tm for each fragment and the barcode oligo hybridization site were calculated using the Integrated DNA Technologies OligoAnalyzer Tool with the settings: Oligo conc. $=0.05 \mu \mathrm{M}, \mathrm{Na}^{+}$conc. $=50 \mathrm{mM}, \mathrm{Mg}^{++}$conc. $=10 \mathrm{mM}$, dNTPs conc. $=0 \mathrm{mM}$. (B) Overview of the $\mathrm{P}_{\mathrm{RA} 1}$ barcoding procedure. dU nucleotides are excised so that a barcoding oligo can be annealed and ligated to the DNA template. The DNA template is immobilized on streptavidin beads so that excess barcoding oligo can be removed before primer extension to fill the 5 ' overhang. (C) Proof-of-principle for $\mathrm{P}_{\mathrm{RA} 1}$ barcoding using a 5' biotinylated DNA. (D) Validation of $\mathrm{P}_{\mathrm{RA} 1}$ barcoding with an internal biotin-TEGmodified DNA template through the DNA immobilization step. (E) Comparison of DNA polymerases for filling a 5 ' overhang on an internal biotin-TEG-modified DNA template. $(F)$ Native PAGE comparing input DNA to barcoded DNA. All gels are representative of two independent replicates. 
bioRxiv preprint doi: https://doi.org/10.1101/2021.03.15.435517; this version posted March 15, 2021. The copyright holder for this preprint (which was not certified by peer review) is the author/funder, who has granted bioRxiv a license to display the preprint in perpetuity. It is made available under aCC-BY-NC-ND 4.0 International license.

A

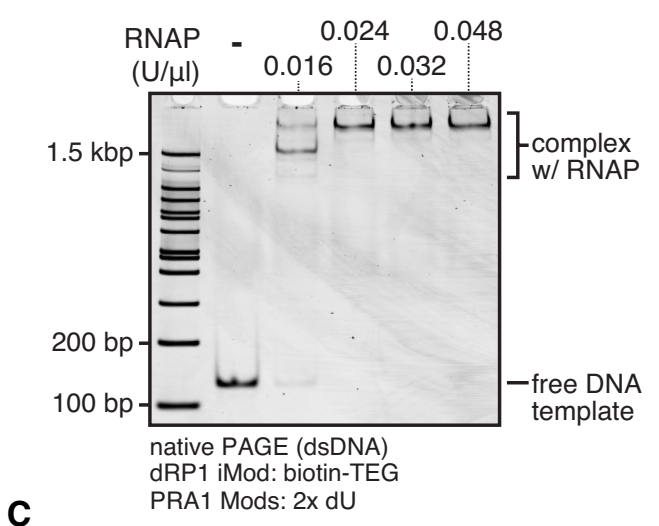

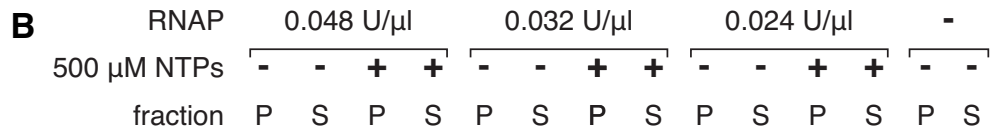

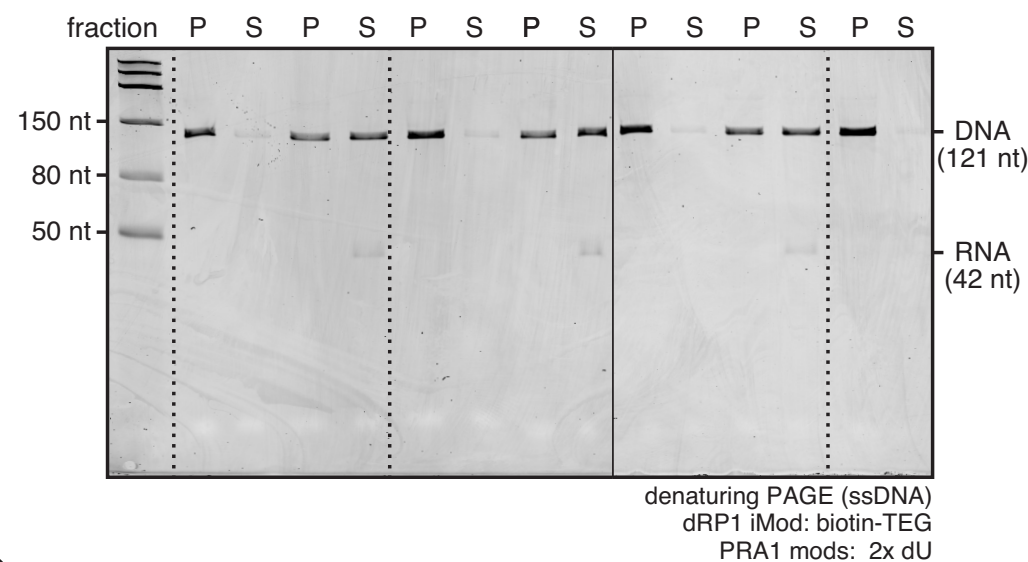

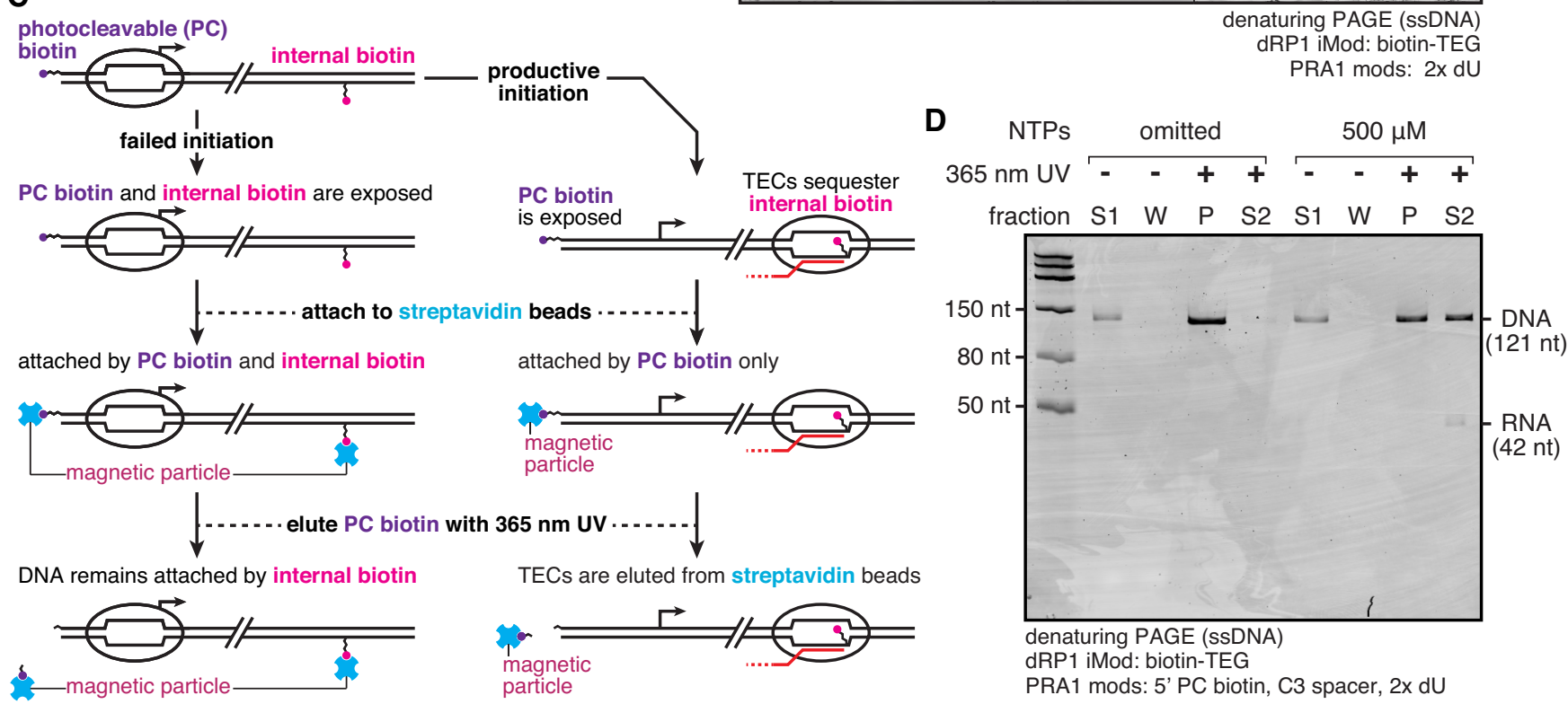

Figure 3. Selective elution of roadblocked TECs from streptavidin beads. (A) EMSA of open complexes formed with $5 \mathrm{nM}$ DNA template and variable concentrations of $E$. coli RNAP. (B) Fractionation of internal biotin-TEG-modified DNA template following transcription with variable concentrations of $E$. coli RNAP in the presence and absence of NTPS. P = Pellet, $S=$ Supernatant. The solid vertical line between 0.032 and 0.024 $U / \mu$ l samples indicates a gel splice. (C) Overview of a strategy for purification of TECs. If RNAP fails to escape the promoter, DNA is attached to streptavidin beads by both PC biotin and internal biotin-TEG. If RNAP escapes the promoter, internal biotin-TEG is sequestered by a TEC, so that DNA is only attached to streptavidin beads by PC biotin. TECs can therefore be selectively photo-eluted by $365 \mathrm{~nm}$ UV. (D) Proof-ofprinciple of the TEC purification procedure shown in (C). S1 is the supernatant after bead binding, $\mathrm{W}$ is the supernatant after a wash step to remove transcription reaction components, $\mathrm{P}$ is the pellet, and $\mathrm{S} 2$ is the supernatant following photo-elution. The experiment in $(A)$ was performed once to set conditions for $(B)$ and (D). The gels in (B) and (D) are representative of two independent replicates. 
bioRxiv preprint doi: https://doi.org/10.1101/2021.03.15.435517; this version posted March 15, 2021. The copyright holder for this preprint (which was not certified by peer review) is the author/funder, who has granted bioRxiv a license to display the preprint in perpetuity. It is made available under aCC-BY-NC-ND 4.0 International license.
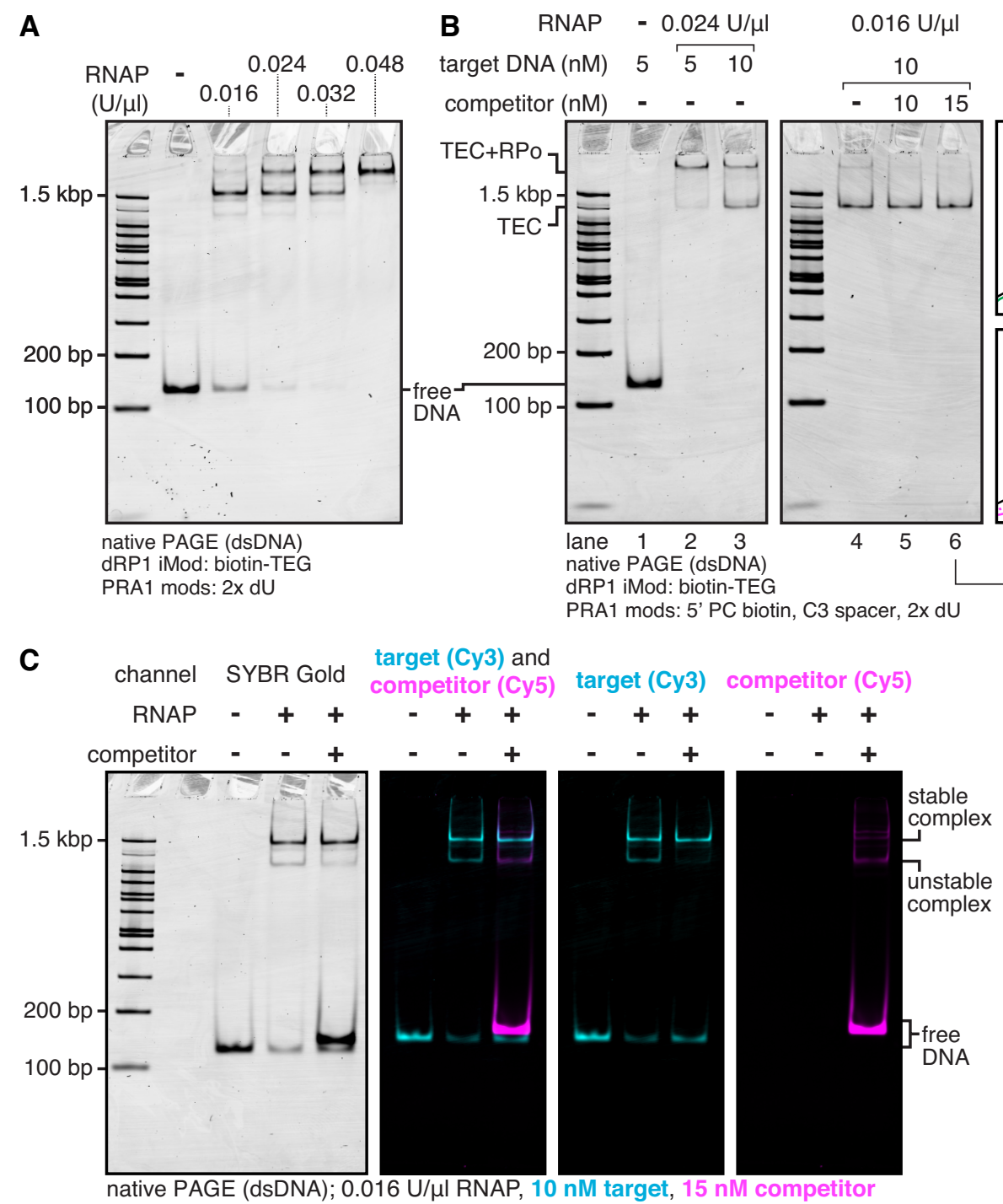

\section{B RNAP $\quad-0.024 \mathrm{U} / \mu \mathrm{l} \quad 0.016 \mathrm{U} / \mu \mathrm{l}$}

target DNA (nM) $5 \longdiv { 5 1 0 }$

competitor $(\mathrm{nM}) \quad$ - $\quad$ - $\quad$ -

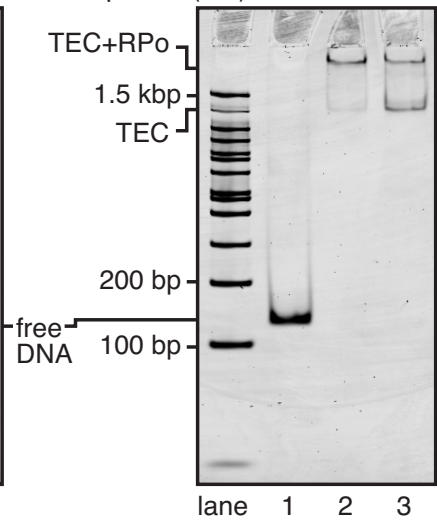

lane $122 \stackrel{3}{ }$ native PAGE (dsDNA)

dRP1 iMod: biotin-TEG
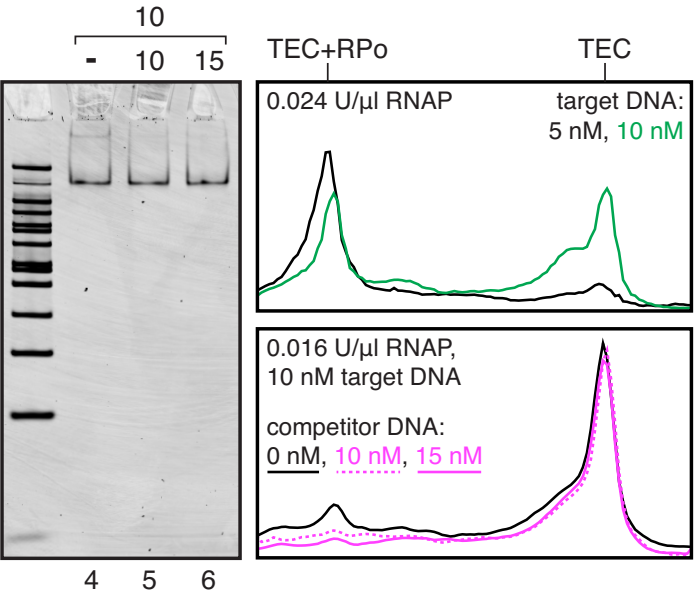
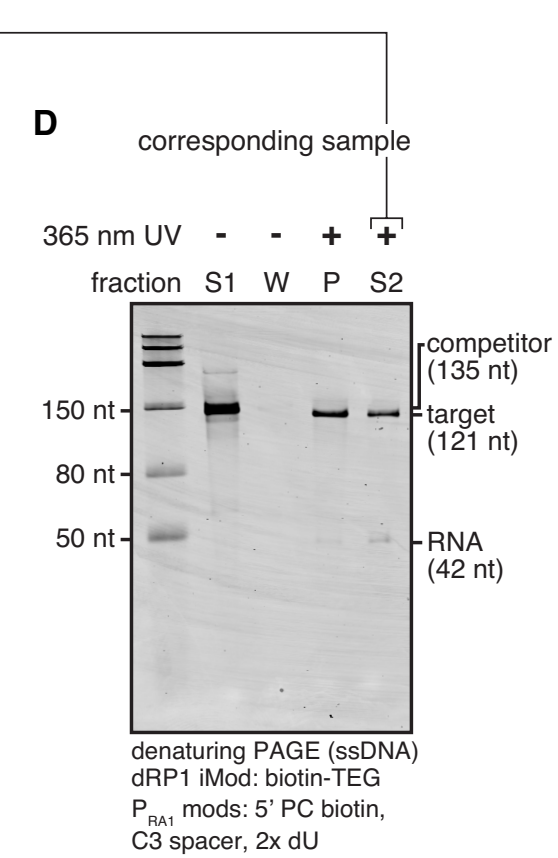

Figure 4. Optimization of TEC purification. (A) EMSA of open complexes formed with 10 nM DNA template and variable concentrations of E. coli RNAP. (B) EMSA of TECs purified with variable DNA template, RNAP, and competitor DNA template concentrations. The assay shown in Figure 5 revealed the slow-migrating band to be TECs with an associated open promoter complex, and the fast-migrating band to be pure TECs. Independent TEC preparations using the $0.016 \mathrm{U} / \mu \mathrm{l}$ RNAP, $10 \mathrm{nM}$ target DNA, and $15 \mathrm{nM}$ competitor DNA condition from lane 6 are shown in Figures S2, S3A, and S3B. (C) EMSA of sequentially formed of open complexes with Cy3-labelled target and Cy5-labelled competitor DNA. (D) Denaturing PAGE of purification fractions for TECs prepared using the conditions in (B) lane 6. S1 is the supernatant after bead binding, W is the supernatant after a wash step to remove transcription reaction components, $P$ is the pellet, and $S 2$ is the supernatant following photo-elution. The experiment in $(A)$ was performed once to set conditions for (B), (C), and (D). The gels in (B), (C), and (D) are representative of two independent replicates. 
A

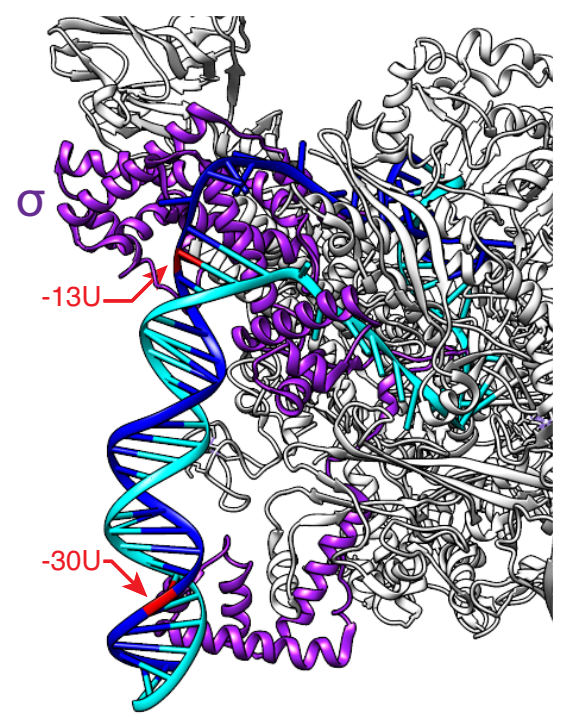

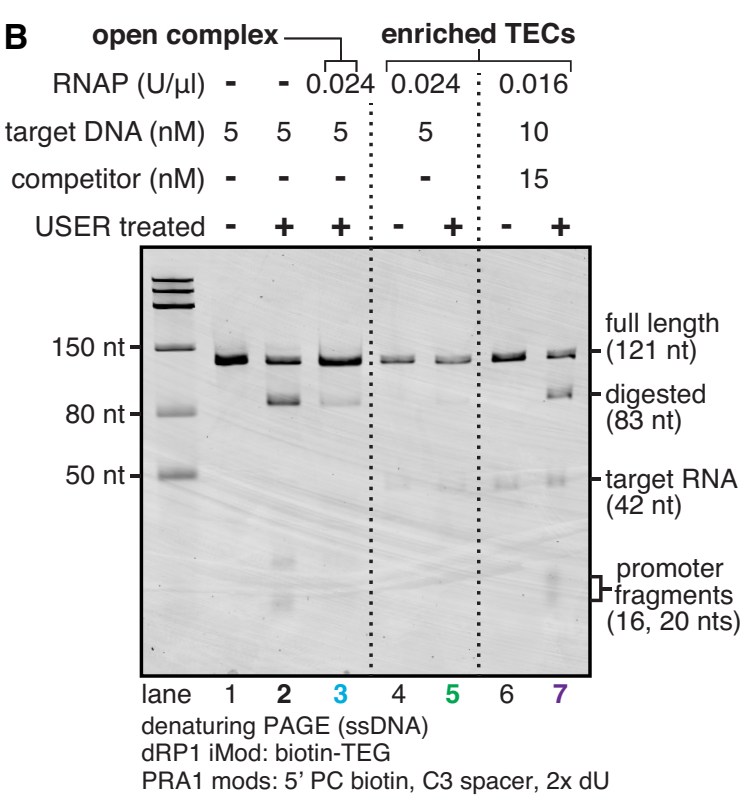

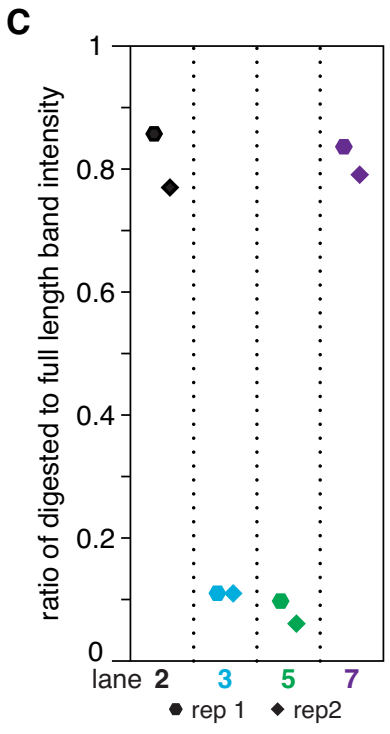

Figure 5. USER ${ }^{\circledR}$ footprinting to assess promoter accessibility. (A) Structure of Thermus aquaticus open promoter complex (PDB:4XLN) (50) annotated to indicate the position of $\mathrm{P}_{\mathrm{RA} 1} \mathrm{dU}$ bases relative to direct contacts between $\sigma$ and promoter DNA. (B) USER ${ }^{\circledR}$ footprinting assay to assess PRA1 $_{\text {promoter accessibility. }}$. Saturation of the $\mathrm{P}_{\mathrm{RA} 1}$ promoter with open complexes (conditions from Figure 3A) attenuates USER ${ }^{\circledR}$ digestion. TECs prepared under conditions that predominantly yield slow-migrating complexes (Figure 4B, lane 2) inhibit USER ${ }^{\circledR}$ digestion, indicating promoter occupation by open complexes. TECs prepared under conditions that yield $>97 \%$ fast-migrating complexes (Figure $4 \mathrm{~B}$, lane 6 ) are efficiently digested, indicating the absence of open complexes. (C) Quantification USER ${ }^{\circledR}$ digestion for key lanes from (B) as the ratio of USER ${ }^{\circledR}$ digested to full length band intensity. The gel in $(B)$ is representative of two independent replicates. 


\section{Preparation of $E$. coli RNA polymerase transcription elongation complexes for systematic RNA assays}

\section{Eric J. Strobel}

\section{Materials Included:}

Figure S1. Verification of 5' PC Biotin photocleavage using a custom $365 \mathrm{~nm}$ microcentrifuge tube irradiator.

Figure S2. Comparison of TEC purification conditions.

Figure S3. Integration of TEC purification with USER barcoding.

Figure S4. Quality control for internally modified DNA template preparations.

Table S1. Oligonucleotides used in this study.

Table S2. DNA templates prepared for this study. 

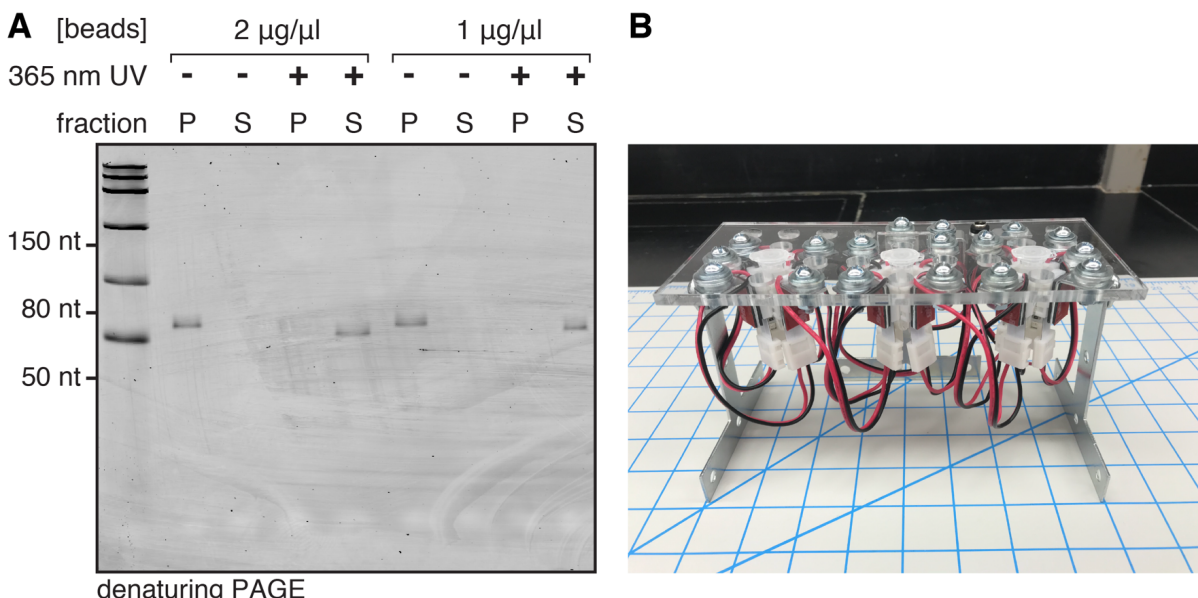

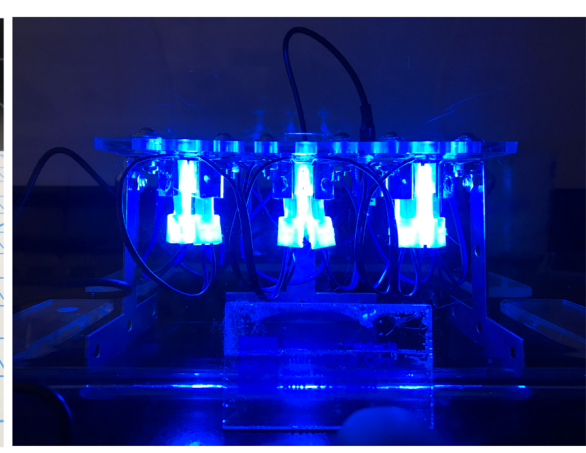

Figure S1. Verification of 5' PC Biotin photocleavage using a custom $365 \mathrm{~nm}$ microcentrifuge tube irradiator. (A) Denaturing gel showing efficient 365 nm UV-dependent release of a 5' PC biotin-modified oligonucleotide from two concentrations of streptavidin-coated magnetic beads. (B) Custom built $365 \mathrm{~nm}$ tube irradiator. 

available under aCC-BY-NC-ND 4.0 International license.

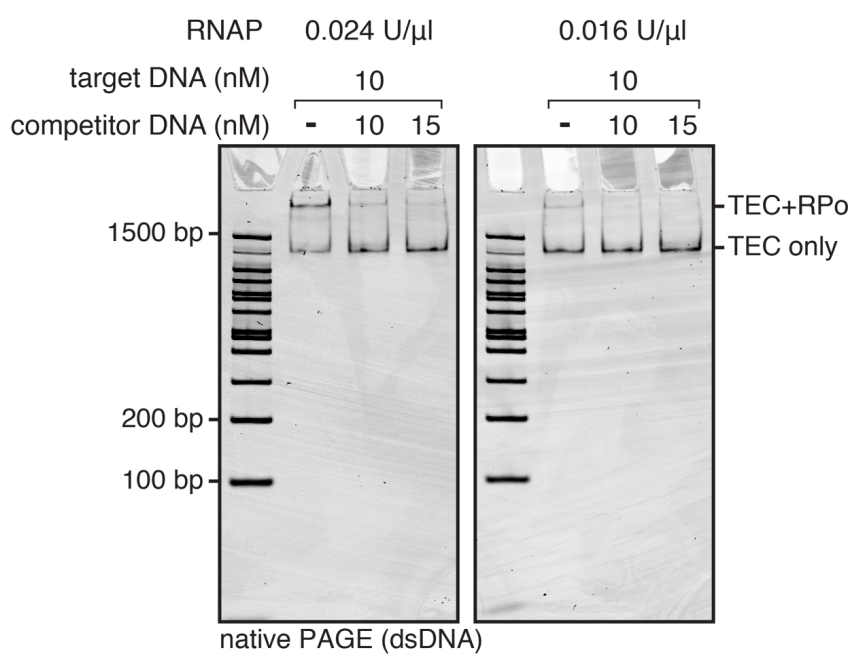

Figure S2. Comparison of TEC purification conditions. EMSA of TECs purified using variable RNAP and competitor DNA concentrations. The gel containing $0.016 \mathrm{U} / \mu \mathrm{l}$ RNAP samples is a replicate of the corresponding gel shown in Figure 4B shown here for comparison to the $0.024 \mathrm{U} / \mu \mathrm{l}$ RNAP samples, and to illustrate the reproducibility of the purification. 

available under aCC-BY-NC-ND 4.0 International license.

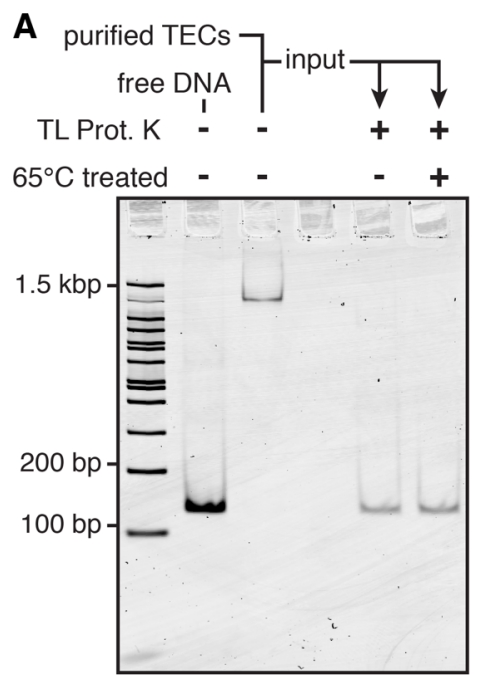

B

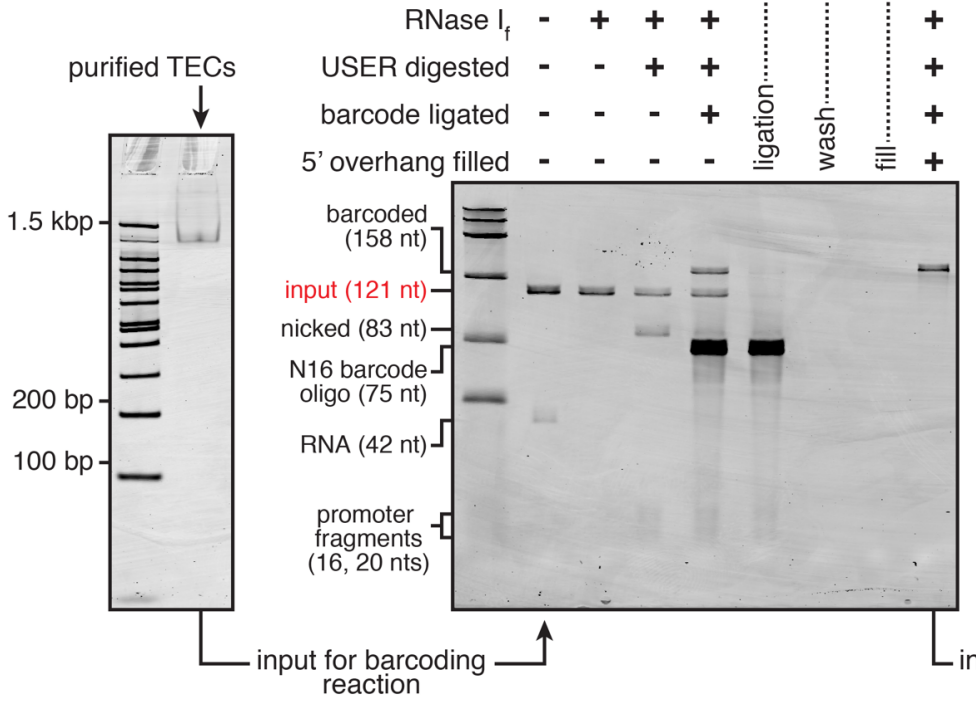

PCR cycles

w/ $2 \mu$ input

$3 \quad 4 \quad 5$

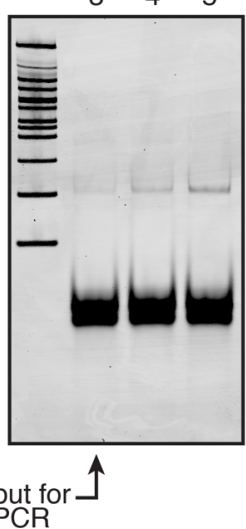

Figure S3. Integration of TEC purification with USER barcoding. (A) Degradation of purified TECs using

Thermolabile Proteinase K (TL Prot. K) followed by heat treatment at $65^{\circ} \mathrm{C}$. (B) Stepwise visualization of the USER barcoding procedure beginning from a single pool of purified TECs. 

available under aCC-BY-NC-ND 4.0 International license.
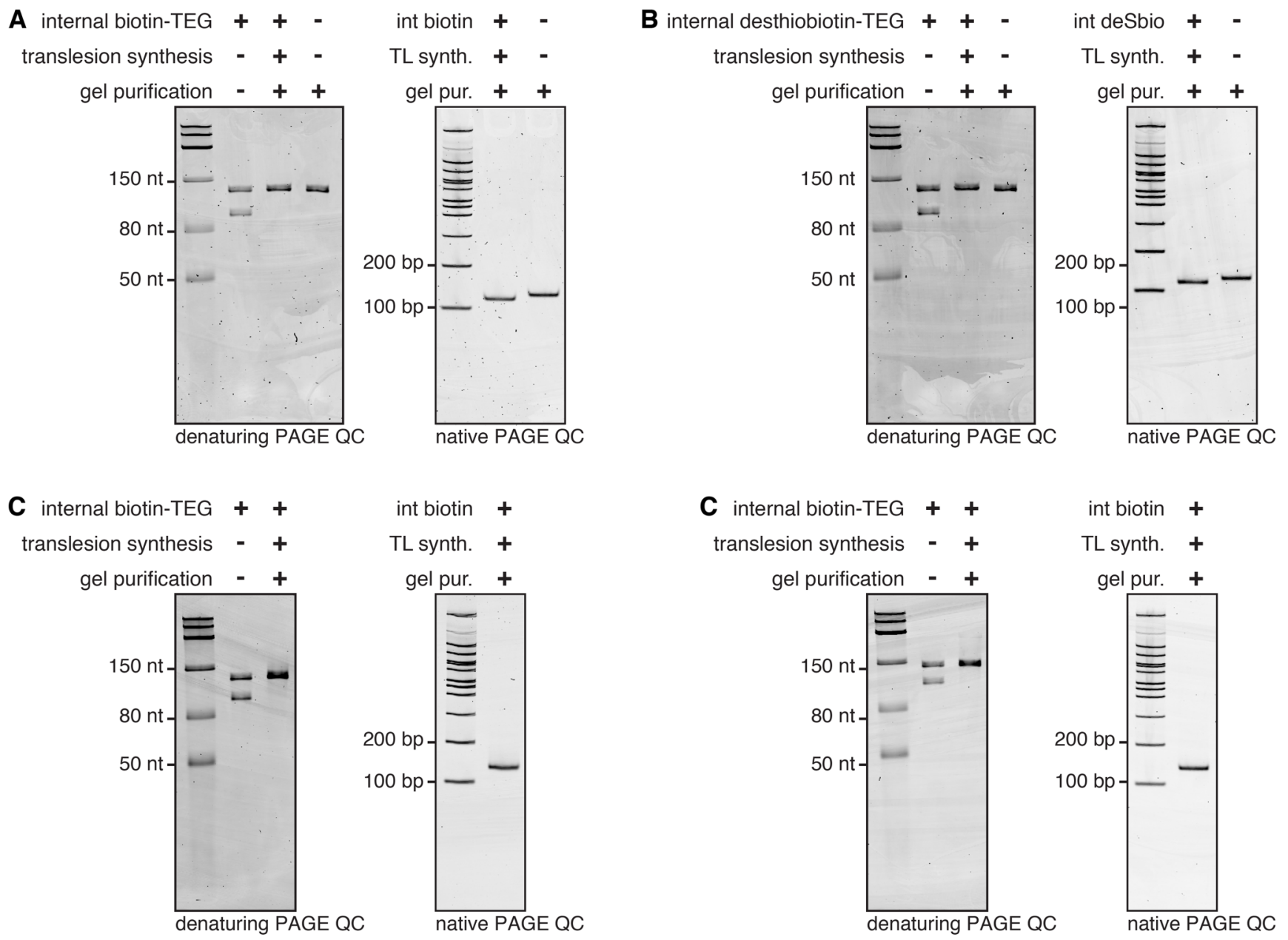

Figure S4. Quality control for internally modified DNA template preparations. Denaturing and nondenaturing quality control of (A) DNA template 2 , (B) DNA template 3, (C) DNA template 4, and (D) DNA template 5. Details of each DNA template preparation are available in Table S2. In Panels A and B, DNA Template 1 is used as a positive control DNA that did not contain an internal modification in both the denaturing and non-denaturing quality control gels. The presence of an internal modification causes a slight mobility shift relative to DNA without an internal modification. 
Table S1. Oligonucleotides used in this study. Below is a table of oligonucleotides used for the preparation of in vitro transcription DNA

templates. The modification codes defined below are used for compatibility with Integrated DNA Technologies ordering. DNA containing internal

biotin-TEG and internal etheno-dA requires an off-catalog order.

/ideSBioTEG/: internal desthiobiotin-triethylene glycol

/iBiotinTEG/: internal biotin-triethylene glycol

/iEth-dA/: internal etheno-dA

/ideoxyu/: internal deoxyuridine

/5PCBio/: 5' photocleavable biotin

/5bioSG/: "standard" 5" biotin

/5Cy5/: 5' Cy5 dye

$/ 5 \mathrm{Cy}^{3} /: 5^{\prime}$ Cy 3 dye

\begin{tabular}{|l|l|l|l|}
\hline ID & Name & Sequence & Purif. \\
\hline TECD000 & dRP1idSB.R & AATGATACGGCGACCACCGAGATCTACAC/ideSBioTEG/GTTCAGAGTTCTACAGTCCGACGATC \\
\hline TECD001 & dRP1iBio.R & AATGATACGGCGACCACCGAGATCTACAC/iBiotinTEG/GTTCAGAGTTCTACAGTCCGACGATC \\
\hline TECD002 & dRP1iEthdA.R & AATGATACGGCGACCACCGAGATCTACAC/iEth-dA/GTTCAGAGTTCTACAGTCCGACGATC \\
\hline TECD006 & PRA1_NoMod.F & TTATCAAAAAGAGTATTGACTCTTTTACCTCTGGCGGTGATAATGGTTGCAT \\
\hline TECD007 & PRA1_2dU.F & TTATCAAAAAGAGTATTGAC/ideoxyU/CTTTTACCTCTGGCGG/ideoxyU/GATAATGGTTGCAT \\
\hline TECD009 & PRA1_2dU_PCbio.F & /5PCBio//iSpC3/TTATCAAAAAGAGTATTGAC/ideoxyU/CTTTTACCTCTGGCGG/ideoxyU/GATAATGGTTGCAT & HPLC \\
\hline TECD016 & wlk29.tmp & ACCTCTGGCGGTGATAATGGTTGCATGGAGAGGGATATAGGGAAAGTGGTGGACGATCGTCGGACTGTAGAACTCTGAAC & PAGE \\
\hline LEGH67 & LZV3.tmp & ACCTCTGGCGGTGATAATGGTTGCATATTAGATATTAGTCGATCGTCGGACTGTAGAACTCTGAAC \\
\hline LEGI09 & PRA1m12_VRA5_16N & CCTTGGCACCCGAGAATTCCANNNNNNNNNNNNNNTTATCAAAAAGAGTATTGACTCTTTTACCTCTGGCGGT \\
\hline LEGI10 & dRP1_5bio.R & /5bioSG/AATGATACGGCGACCACCGAGATCTACACGTTCAGAGTTCTACAGTCCGACGATC \\
\hline EJS017 & dRP1_NoMod.R & AATGATACGGCGACCACCGAGATCTACACGTTCAGAGTTCTACAGTCCGACGATC \\
\hline EJS029 & dRP1_Cy5.R & /5Cy5/AATGATACGGCGACCACCGAGATCTACACGTTCAGAGTTCTACAGTCCGACGATC \\
\hline EJS030 & pRA1_2dU_Cy3.F & /5Cy3/TTATCAAAAAGAGTATTGAC/ideoxyU/CTTTTACCTCTGGCGG/ideoxyU/GATAATGGTTGCAT \\
\hline RPI1 & RPI1 & CAAGCAGAAGACGGCATACGAGATCGTGATGTGACTGGAGTTCCTTGGCACCCGAGAATTCCA \\
\hline
\end{tabular}


Table S2. DNA templates prepared for this study. Below is a table of DNA templates that were prepared for this study, including the primers and template oligos used, DNA modifications, the PCR polymerase used, whether translesion synthesis was performed, which reaction clean up protocol was used (see Experimental Procedures), and the figures in which each DNA template was used.

\begin{tabular}{|c|c|c|c|c|c|c|c|c|}
\hline ID & Fwd Primer & Rev Primer & $\begin{array}{c}\text { Template } \\
\text { Oligo }\end{array}$ & Modifications & $\begin{array}{c}\text { PCR } \\
\text { Polymerase }\end{array}$ & $\begin{array}{l}\text { Translesion } \\
\text { Synthesis }\end{array}$ & Clean Up & Used in Fig(s) \\
\hline 1 & TECD007 & LEGI10 & LEGH67 & $\begin{array}{l}-13,-30 \mathrm{dU} ; \\
\text { 5' biotin-TEG }\end{array}$ & Q5U & $\mathrm{N} / \mathrm{A}$ & Gel Extracted & $2 \mathrm{C}$ \\
\hline 2 & TECD007 & TECD001 & LEGH67 & $\begin{array}{l}-13,-30 \mathrm{dU} ; \\
\text { Int biotin-TEG }\end{array}$ & Q5U & Yes & Gel Extracted & $2 \mathrm{D}, 2 \mathrm{E}, 3 \mathrm{~A}, 3 \mathrm{~B}, 4 \mathrm{~A}, \mathrm{~S} 4$ \\
\hline 3 & TECD007 & TECD000 & LEGH67 & $\begin{array}{l}-13,-30 \mathrm{dU} ; \\
\text { Int desthiobiotin- } \\
\text { TEG }\end{array}$ & Q5U & Yes & Gel Extracted & $2 \mathrm{~F}, \mathrm{~S} 4$ \\
\hline 4 & TECD009 & TECD001 & LEGH67 & $\begin{array}{l}\text { 5' PC biotin; } \\
\text { Int C3 spacer; } \\
\text {-13,-30 dU; } \\
\text { Int biotin-TEG }\end{array}$ & Q5U & Yes & $\begin{array}{l}\text { Thermolabile Exol } \\
+ \text { PCR clean-up }\end{array}$ & $\begin{array}{l}\text { 3D, 4B, 4D, 5B, S2, S3A, S3B, } \\
\text { S4 }\end{array}$ \\
\hline 5 & TECD006 & TECD002 & TECD016 & Int etheno-dA & Q5 & Yes & $\begin{array}{l}\text { Thermolabile Exol } \\
+ \text { PCR clean-up }\end{array}$ & 4B, 4D, 5B, S2, S3A, S3B, S4 \\
\hline 6 & EJS030 & EJS017 & LEGH67 & $\begin{array}{l}5, \text { Cy3 } \\
-13,-30 \mathrm{dU} ;\end{array}$ & Q5U & $\mathrm{N} / \mathrm{A}$ & $\begin{array}{l}\text { Thermolabile Exol } \\
+ \text { PCR clean-up }\end{array}$ & $4 \mathrm{C}$ \\
\hline 7 & TECD007 & EJS029 & TECD016 & $\begin{array}{l}-13,-30 \mathrm{dU} ; \\
\text { 5' Cy5 }\end{array}$ & Q5U & $\mathrm{N} / \mathrm{A}$ & $\begin{array}{l}\text { Thermolabile Exol } \\
+ \text { PCR clean-up }\end{array}$ & $4 \mathrm{C}$ \\
\hline
\end{tabular}

